
(c) Kent State University 2015. All rights reserved. Duplication of the material contained herein is strictly prohibited without the express written consent of the Editor of The Journal of SPORT.

ISBN-13: 978-1519671530

ISBN-10: 151671539 ISSN:

2328-7624 


\section{Contents}

Culturally Insensitive Athletic Mascots: Do Future Leaders in Sport Care Rickabaugh \& Rickabaugh

Creation and Instruction of a Coach-Implemented Mental Periodization Plan Stonecypher, Leitzelar, \& Judge 12

Understanding college females' intrinsic motives for physical activity: A qualitative comparison between athletes and non-athletes Cronon, Biber, Czech .26

An Analysis of the Factors and Marketing Techniques Affecting Attendance at NCAA Division I Women's Basketball Games Martinson, Schneider, McCullough... .42

About The Journal of Sport...............................................60 



\author{
Culturally Insensitive Athletic Mascots: Do Future Leaders in Sport Care? \\ Timothy E. Rickabaugh \\ Defiance College \\ Eric W. Rickabaugh \\ Rickabaugh Graphics, Inc.
}

\begin{abstract}
Since the passage of the 1964 US Civil Rights Act, insensitive cultural imagery has received ever-increasing scrutiny and opposition, thus many US universities have reconsidered their usage of culturally insensitive athletic mascots (CIAM). A primary goal of this article was to present information on the adoption, evolution, opposition, and, in most cases, transition away from CIAM. Regarding the historic usage and evolution of specific CIAM's, this article will provide a detailed examination of Chief Illiniwek (University of Illinois), Colonel Reb (University of Mississippi), and The Fighting Souix (University of North Dakota).

Another goal was to explore the opinions of traditional-age college students in academic majors related to sport leadership. In order to explore this topic, a survey ( $\mathrm{N}=$ 142) was conducted regarding sport science student reactions to graphic images of CIAM. This survey was conducted to examine the potential effect of Color Blind Racial Ideology (CBRI) regarding CIAM. These findings provide support to the theory that future sport leaders also tend to exhibit CBRI related to school-based athletic mascots where dominant ethnic group perspectives have been the traditional viewpoint.
\end{abstract}




\section{Introduction:}

Over the past thirty years, US universities have faced ever-increasing pressure to drop what many perceive as culturally insensitive athletic mascots (CIAM). The most frequently targeted mascots have been associated with American Indian imagery, but other mascots, such as the use of "lady" for women's teams, have also been identified as being insensitive and/or inappropriate imagery. Pressure to address culturally insensitive imagery was initially fueled by the passage of Title VI of the 1964 Civil Rights Act which established federal regulations providing that "no recipient (of federal funding) can cause or allow a racially hostile environment (Bacca, 2004, p. 73).” The Office of Civil Rights subsequently established the standard for a violation of this act as "any environment that is severe enough to adversely affect the enjoyment (for at least one individual) of some aspect of an educational program (Bacca, 2004, p. 74)." With over 1,400 US educational institutions using CIAM based upon American Indian symbols, major public universities have been the primary targets of complaints due to their high degree of regional, national, or international visibility (King, 2004, p. 3). Figure 1 (below) provides information on some of the notable changes in CIAM's since 1990:

\begin{tabular}{lcll}
\multicolumn{2}{c}{ Figure 1. Notable Changes in Culturally Insensitive University Athletic Mascots } \\
Univer 1990 & \\
University & Year & Former Mascot & New Mascot \\
\hline Saint Mary's University & 1990 & Redmen & Cardinals \\
Eastern Michigan university & 1991 & Hurons & Eagles \\
Marquette University & 1994 & Warriors & Golden Eagles \\
St. John's University & 1995 & Redmen & Red Storm \\
University of Kentucky & 1995 & Lady Kats & Wildcats (for all teams) \\
Miami University & 1997 & Redskins & Red Hawks \\
New Mexico State University & 2000 & Road Runners (women only) & Aggies (for all teams) \\
Colgate University & 2001 & Red Raiders & Raiders \\
Quinnipiac University & 2002 & Braves & Bobcats \\
University of the Cumberlands & 2005 & Patriots & Indians \\
Indiana University of Pennsylvania 2006 & Indians & Crimson Hawks \\
Southeastern Oklahoma State U.2006 & Savages & Savage Storm \\
University of Louisiana-Monroe2006 & Indians & Red Hawks \\
Arkansas State University & 2008 & Indians & Red Wolves \\
University of Rio Grande & 2008 & Redmen/Redwomen & Red Storm \\
Washburn University & 2013 & Lady Braves & Ichabods (for all teams)
\end{tabular}

NOTE: 19 universities were (are) involved in an appeal process with the NCAA to keep their current mascot.

Source: Staurowsky, E. (2007) 
Sport sociologists and racial theorists have presented theories to explain the impact of CIAM on both dominate ethnic groups and ethnic minority populations. Farnell (2004) proposed that the use of CIAM creates "White Public Space”, founded upon ethnification and racialization, within which Whites are "invisibly normal" and racialized populations are "visibly marginal". King (2004, p. 5) further stated that the specific use of American Indian mascots "claims the right to assess the propriety, acceptability, and authenticity (of American Indian populations) in White terms (and) in White-centered, White-identified, and White-dominated contexts.” This White Public Space is a somewhat abstract concept, but it was clearly described by Grant Teaff (former football coach at McMurry University) when he stated (Staurowsky, 2007, p. 64) that "You know, we are all Indian. At least those of us from McMurry anyway. We are all McMurry Indians, and we always will be."

\section{The Impact of Culturally Insensitive Imagery}

This section will address the impact of CIAM usage on both ethnic minority and ethnic majority populations. The impact of culturally insensitive imagery is most often gradual and subliminal in nature. Nevile, et al (2011, p. 238) found that constant exposure to stereotyped American Indian images (such as the Cleveland Indians usage of Chief Wahoo and The University of Illinois usage of Chief Illiniwek) were related to "negative psychosocial outcomes including lower self-esteem and community worth" among American Indian students. Staurowosky (2007) added that with $40 \%$ of American Indian students dropping out of High School, there may be serious side-effects of institutionalized, negative cultural imagery of American Indian populations. Neville et al (2011, p. 238) reported that usage of negative cultural imagery also "creates a hostile learning environment for those attending schools with racialized mascots."

Usage of CIAM can also affect the mindset of youth within dominant ethnic populations as well. Bacca (2004, p. 72) proposed that members of dominant ethnic populations should "imagine a t-shirt or jacket with a pejorative against any other race or ethnic group - nigger, wop, kike, slope, spic - being allowed at a workplace or school”" and added "yet some public schools use the term redskin as an official mascot and display it proudly on uniforms." One primary outcome of CIAM usage is what Neville, et al (2011, p. 236) have described as Color Blind Racial Ideology (CBRI). They described CBRI as "the belief that race and racism are now irrelevant for the contemporary movement."

CIAM's are not necessarily limited to graphic images alone. The ritualistic behaviors of "human mascots" also can portray stereotypical characteristics of minority populations. To further investigate this phenomenon, they surveyed 389 University of Illinois students about the use of the Chief Illiniwek symbol and his pre-game dance. This pre-game dance ritual was described by Farnell (2004, p. 32) as a "White, male, student dressed and painted as an Indian who choreographs colonialism in every step of his cavorting fancy dance.” Of the students surveyed, 53\% were strongly in support of 
keeping “The Chief”; 25\% were opposed to his usage; and 22\% didn't appear to care one way or the other. Regarding the usage of Colonel Reb (at the University of Mississippi), a campus poll taken during the fall of 2003 indicated that $94 \%$ of students wanted to keep "The Colonel" as the school's athletic mascot despite what he may represent to any ethnic minority population. It may be that the current generation of traditional-aged college students views civil rights as a battle that has already been won and thus have adopted CBRI as a "path of least resistance".

The counter-argument to replacing CIAM's is most commonly based upon the ethnic majority's stereotypical views of ethnic minority populations. Steinfeldt and Wong (2010, p. 110) describe this phenomenon as a "consumer blind spot within the dominant White culture" which "inhibits the ability of many Americans to identify the potential for these images to be perceived as racist and offensive.” Neville et al (2011, p. 237) described the current situation (in the US) as one in which the prevalent ideology does not necessarily align with reality. They proposed that many young people feel that they exist in an "ideal world (where) it would be desirous if race did not matter and that all were treated equally as human beings" when (in reality) "the US is a racially stratified society in which racism exists on many levels including individual and institutional”.

\section{History and Evolution of Typical Culturally Insensitive Athletic Mascots}

This section provides information related to the history and evolution of three highly visible and traditional CIAM's. To fully appreciate the significance of CIAM it is necessary to explore examples of their history and evolution. During the 1920s and 1930s, many US colleges and universities playfully adopted what we view now as CIAM (King, 2004; Newman, 2007; Steinfeldt, et al, 2010). Some, such as the University of Illinois, with Chief Illiniwek, claimed to honor the American Indian Tribe that once thrived within their geographic region, while others, such as the University of Mississippi with Colonel Reb, harkened back to what they (ethnic majority populations) viewed to be regional heritage and tradition. These symbols of the power of the White majority were largely unchallenged during pre \& post World War II eras, and many more specific "layers" of tradition were added as years went by. For instance, Colonel Reb began to wear a Confederate Army uniform most often accompanied by the Dixie anthem and the Confederate flag (Newman, 2007). The University of Illinois created an elaborate, traditional pre-game dance during which Chief Illiniwek was supposedly honoring "Illini tribal heritage and traditions” (Farnell, 2004). Figure 2 (below) provides detailed information on the creation, symbolism, opposition to, and current status of three typical university CIAM's: 
Figure 2. History and Evolution of Three Culturally Insensitive Athletic Mascots Phase Time Period/Evolutionary Process

$\begin{array}{rcrl}\text { Creation: } & 1926 & \text { Chief Illiniwek } & \begin{array}{l}\text { Mascot chosen and developed by a former Boy Scout } \\ \text { attending University of Illinois } \\ \text { University of Mississippi students drop "The Flood” and } \\ \text { select “Colonel Reb” }\end{array} \\ 1936 & \text { Colonel Reb } & \text { Fighting Souix } & \begin{array}{l}\text { University of North Dakota students drop "Flickertails” and } \\ \text { select "Fighting Souix" }\end{array}\end{array}$

\section{Symbolism:}

Chief Illiniwek: Primarily focused upon ceremonial headdress logo and pre-game "Chief Dance” ritual

Colonel Reb: Associated with Confederate flag, Dixie anthem, Southern plantations, and terms such as “Old South”, "Rebels”, “Old Massas”, “General Nat”, “Johnny Reb”, and “Ole Miss”

Fighting Souix: Mascot popularized for being “warlike” and known for exterminating bison (mascot for

\section{Opposition:} rival University of North Dakota)

Chief Illiniwek: Mascot and dance reported to be inauthentic in honoring Illini tribal traditions (1990), opposed by NCAA in 2005, dance last performed on campus in 2007

Colonel Reb: Barred from wearing Confederate uniform in 1979, use of Confederate flags in stadium/arena prohibited in 1997, plan to replace Colonel Reb announced by University officials in 2003

Fighting Souix: Usage opposed by tribal leaders, American Indian UND student groups, and the NCAA (1969 to 2005)

\section{Current Status:}

Chief Illiniwek: Mascot, logo, and dance dropped by the University of Illinois; nickname "Illini" still utilized

Colonel Reb: Mascot dropped and replaced by "Rebel the Black Bear”; nickname "Rebels” still utilized

Fighting Souix: Still appealing the NCAA mandate to discontinue usage of mascot and nickname

Sources: Farnell, B. (2004); King, C.R. (2004); Newmann, J.I. (2007); Steinfeldt, J.A, Kaladow, J.K., Pagano, L.A., \& Steinfeldt, M.C. (2010)

As the US Civil Rights movement of the 1960s progressed, the collective voice of ethnic minority populations, and the scrutiny of cultural imagery, increased. Subsequently, institutions such as Stanford University (Indians to Cardinals then Cardinal) and Eastern Michigan University (Hurons to Eagles) chose to drop mascots based upon ethnification and/or racialization. However, most institutions have resisted external and internal pressure for change. 
A typical resistance movement (to the usage of a CIAM) occurred on the University of North Dakota campus during 1969. The relatively small population of American Indian students (3\% of enrolled students) formed the UND Indian Association to voice their opposition to the institutional representation of their tribes/nations (Steinfeldt, et al, 2010). Since that time over 21 additional organizations have submitted resolutions asking UND to discontinue their use of their Fighting Souix nickname and mascot (Steinfeldt, et al, 2010). Finally, in 2005, the NCAA mandated that nineteen colleges and universities must discontinue their use of their Native American themed mascots or face future sanctions (Staurowsky, 2007).

\section{Transitioning away from Culturally Insensitive Imagery}

This section will provide information related to the recent pressure to move away from CIAM's. Prior to the 2005 NCAA mandate, many universities were already beginning a gradual transition process away from CIAM. Newman (2007) reported that in 1979 Colonel Reb discontinued wearing the Confederate Army uniform, and in 1997 the University of Mississippi administration barred Confederate flags from intercollegiate athletic venues. Farnell (2004) reported that in 1990 the University of Illinois eventually disclosed that Chief Illiniwek and his pre-game dance were inauthentic regarding the history and traditions of the Illini Tribe. Many of these changes reflected changing societal norms related to insensitive cultural imagery. Former University of Mississippi football coach Steve Sloan commented (Newman, 2007, p. 324) that the institutional usage of racialized imagery and traditions increasingly made recruiting a more difficult process, and that he had to spend "significant time explaining why the racial symbols aren't important or were innocent."

Resistance to change is most often based upon the perception of being forced to discontinue what most view to be the history and traditions of their university. However, such changes are also a significant economic issue. For instance, Old Miss-Colonel Reb themed merchandise (in 2005) generated nearly \$4 million annually for the University of Mississippi (Newman, 2007). Most often, universities wanting to transition away from CIAM will hire consulting and/or graphic design firms to assist with this controversial and complex process.

\section{The Transition Process Away from CIAM's}

This section describes the transition process (from a specific consultant/graphic designer's perspective) often utilized when a university decides to replace a CIAM. With few exceptions, colleges and universities seek to avoid any situation which upsets stakeholders, who typically are strongly opposed to change. If primary stakeholders (alumni, students, faculty, community, or fans) are fond of the current athletic brand, it will require a very compelling outside force to urge schools to undergo a rebranding process. Examples of three external forces strong enough to prompt a branding change include pressure from ethnic minority rights advocacy groups, governing bodies (such as 
the NCAA, NAIA, state or federal government), or the implications of negative media coverage.

The majority of recent rebranding examples have involved the collegiate usage of Native American nicknames and the ongoing pressure for change originating from certain Native American tribes. Initial tribal pressure encouraged the ACLU and other minority rights advocacy groups to champion the Native American cause to the NCAA. Subsequently, the NCAA responded by limiting (in 1995) the rights of any member college or university utilizing a Native American athletic mascot. Ultimately outside pressure usually becomes a stronger force than the school's fear of upsetting their stakeholders and thus many recent branding processes have been implemented. There are additional marketing forces to be considered that can also encourage (or discourage) the athletic rebranding process. These forces include a reduction in sales of logo retail merchandise, an "out-of-date" logo, inconsistent usage of logos, improper brand messaging, or "incomplete" branding families (for example, the lack of a mascot version for children's clothing).

The process of assisting collegiate client transference from "culturally insensitive" athletic brands to updated and less controversial brands can be quite challenging. Stakeholders usually have developed a very strong historic and emotional bond with collegiate athletic logos, thus asking them to leave behind a beloved and cherished tradition can be very difficult. The process normally involves transitioning an angry, volatile environment into a more supportive environment where stakeholders can develop and embrace the new brand. For this reason, the initial phase typically includes preliminary focus groups which offer the school's stakeholders an opportunity to vent their feelings regarding disappointment and unhappiness and to discuss the need for change. Once focus group participants feel that they have been heard and appreciated, they are most often able to channel their emotions towards a more positive direction, discussing options for possible new nicknames and logos, and focusing on creating a new image that they are comfortable with. Based upon focus group input, numerous options can be developed for the look of the new brand and ultimately brand "finalists" are refined until they are completely satisfactory. The finalists are then shared with primary stakeholders to obtain their input, and the final brand is selected and refined for unveiling to the campus community.

Not all sub-groups of stakeholders react similarly to the re-branding process. In general, current students are much more open to change than alumni since they have not lived as long with their traditional collegiate identity. Alumni (as well as members of the local or regional community) often view themselves as being partially defined by athletic logos and traditions, and thus are much more resistant to change. However, despite their openness to change, students can be less sensitive to the need for change. Many students are very sensitive to the needs and feelings of others, often becoming the strongest of advocates for the disenfranchised, but few have enough life experiences to truly understand what it is like to be a member of a discriminated ethnic minority group. Thus, 
color-blind racial ideology is a common barrier to change within this group (Neville et al, 2011; Steinfeldt \& Wong, 2010).

The three most important aspects of managing the transition process are the "Three E"s: "emotion", "education" and "evolution". As you would expect, managing the emotional response to the loss of a beloved symbol is crucial. People who feel an attachment to a culturally insensitive symbol are not necessarily racist or insensitive. They see the logo as symbolizing their love for their school and that love overshadows any negative symbolism involved. During the transition process, they have a right to "grieve" the loss of their memories, traditions, and customs as well as the right to be heard. Once they have had a chance to vent their emotional response they can begin to move forward, focusing upon their rational response to the situation at hand.

The next transition step involves educating stakeholders about the reasons for the change. Once the emotional response has been "released", it is much easier for stakeholders to comprehend the cultural issues involved and to accept that change as inevitable. They also can embrace the marketing advantages that are available with a new nickname and logo. At this point they can often begin to generate excitement, focusing on creating the best new brand possible.

Evolution to the new brand is the final key transition component. It is vital that the new branding image is a genuine reflection of the school's history, traditions, character, and personality. The new brand should not be a slick marketing tool focused upon current trends without regard for the history and traditions of the college community. In fact, the best way to ensure that stakeholders will embrace a new brand is to base it upon adored traditions of the school community.

\section{Exploring the Attitudes of Future Sport Leaders}

This section provides insight into the views of students and then, more specifically, future sport leaders regarding the usage of CIAM. Along with alumni that have lived with the imagery and traditions of the past, most current students are also very resistant to the process of changing CIAM. A 1997 University of Mississippi campus poll reported that $94 \%$ of students surveyed wanted to keep Colonel Reb (Newman, 2007). In a similar study, 389 students were surveyed about their reactions to dropping the Chief Illiniwek imagery and pre-game ritual (Neville, et al, 2011). Of the students surveyed, $53 \%$ were supportive of "The Chief” while only $25 \%$ felt that his usage should be discontinued. In an online poll of 1,699 respondents, Steinfeldt, Kaladow, Pagano, and Steinfeldt (2010, p. 365) identified the primary objections to dropping Native American-themed mascots. The most frequently reported reason (32\%) was that "these people just want attention, (this is) not a legitimate complaint." Other common objections included "we are victims of reverse racism and political correctness" (22\%), "this issue is too trivial to get this amount of attention" (14\%), and "this costs too much and should not be a priority (8\%)." 


\section{Survey of Selected Future Sport Leaders}

In order to further examine the reactions of current traditional-age students about CIAM, we developed a "logo-based" mascot survey and administered it to 142 sport science undergraduate students (Exercise Science, HPE, and Sport Management majors) at a small, Midwestern, liberal arts college. This subject sample of sport science students (as opposed to the university "at large") was selected in order to assess the perspective of students who are required to take courses addressing specific academic areas such as sport history, sport sociology, sport psychology, and sport ethics. It can be assumed that cultural sensitivity and diversity are core concepts to be addressed and that these "future sport leaders" should have become aware of, and sensitive to, issues related to CIAM.

The survey contained the graphic images of seven common athletic mascot images. Three logos were American Indian-themed and one each was associated with nationality/religion, gender, and violence. Students were asked to "rate how culturally insensitive these athletic mascots could seem to any group of people within our (national) society." A one-to-ten Likert scale was utilized and was labeled as follows: 1 = "not insensitive", 5 = "moderately insensitive", 10 = "extremely insensitive". Results of the

Figure 3. survey are presented in Figure 3 (below):

Athletic Mascot Survey Results ( $=142)$

NOTE: Cells contain mean \pm standard deviation

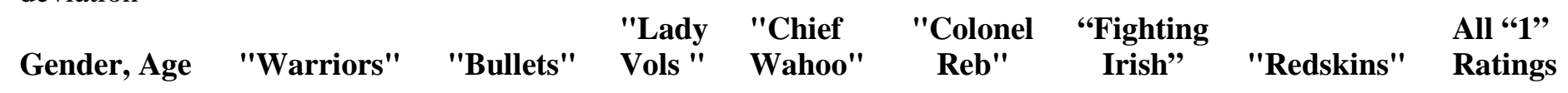

\begin{tabular}{|l|c|c|c|c|c|c|c|l|}
\hline Male, 20.0 & 3.58 & $2.88 \pm$ & 2.27 & 4.69 & 3.75 & 3.53 & 5.56 & $\mathrm{n}=6$ \\
\pm 1.6 & \pm 2.3 & 2.3 & \pm 1.9 & \pm 2.6 & \pm 2.7 & \pm 2.6 & \pm 2.8 & $(6.3 \%)$ \\
\hline
\end{tabular}

\begin{tabular}{|c|c|c|c|c|c|c|c|}
\hline $\begin{array}{l}\text { Female, } 20.6 \\
+3.0\end{array}$ & $\begin{array}{r}3.43 \\
+1.9\end{array}$ & $\begin{array}{r}2.26 \\
+2.0\end{array}$ & $\begin{array}{r}2.48 \\
+1.8\end{array}$ & $\begin{array}{l}4.10 \pm \\
2.3\end{array}$ & $\begin{array}{r}3.62 \\
+2.1\end{array}$ & $\begin{array}{r}3.79 \\
+2.4\end{array}$ & $\begin{array}{r}4.57 \\
+2.8\end{array}$ \\
\hline $\begin{array}{l}\text { Rating } \\
\text { greater than } \\
\text { "5"; } \mathbf{n}(\%)\end{array}$ & $\begin{array}{c}33 \\
(23.2 \%)\end{array}$ & $\begin{array}{c}15 \\
(10.6 \%)\end{array}$ & $\begin{array}{c}14 \\
(9.9 \%)\end{array}$ & $\begin{array}{c}41 \\
(29.0 \%)\end{array}$ & $\begin{array}{c}31 \\
(22.0 \%)\end{array}$ & $\begin{array}{c}35 \\
(24.6 \%)\end{array}$ & $\begin{array}{c}61 \\
(43.0 \%)\end{array}$ \\
\hline
\end{tabular}

Group-mean scores on the logo survey revealed that most students did not react strongly to any of the athletic logos. Additionally, mean scores were very similar between male and female students, even for the single, gender-related logo. Students reacted most strongly to the American Indian-themed logos utilizing Chief Wahoo and the "Redskin" image. It is also interesting to note that twelve students (8.4\%) rated each 
logo as a 1.0 indicating that they were completely unconcerned with any movement to revise (or eliminate) CIAM.

\section{Conclusion}

The findings of our survey agree with those presented by Steinfeldt \& Wong (2010) and Neville, et al. (2011) indicating that many traditional-age college students display a high degree of Color Blind Racial Ideology (CBRI) when confronted with culturally insensitive imagery. It may be that issues confronted during the US Civil Rights movement are no longer perceived as "contemporary" by traditional-age college students. Additionally, young people may view these historic confrontations as having already been won and no longer societal priorities. However, Neville et al. (2011, p. 237) reported that greater levels of CBRI are associated with "less tolerant racial and social beliefs among students." The CBRI impact on the ethnic majority population, combined with the negative influences on ethnic minority youth being portrayed by mascots, needs to be recognized and discussed within our educational systems. In the academic setting of undergraduate sport science programs, we propose four basic steps to address these issues:

1) First-year undergraduates need to understand the significance of cultural imagery in US sport (and society in general) as well as the processes of ethnification and racialization. Our society is full of compelling case studies within which we could teach about the history, evolution, and impact of culturally insensitive athletic mascots. These outcomes would fit well within introductory-level history, philosophy, and principles courses.

2) Upper-level undergraduate students should understand and appreciate the concepts of White Space and Color Blind Racial Ideology. These social theories would serve as excellent debate topics within any course that addresses the areas of sport sociology, sport history, sport psychology, or sport ethics.

3) Students in organization and administration courses, or sport law courses, should explore legislation related to the use of culturally insensitive imagery. Researching the background of these policies would provide students with a more comprehensive perspective that takes into account the impact of cultural imagery on ethnic minority populations.

4) Finally, when students are placed in off-campus settings for field-experiences or internships, they should discuss this topic with professionals that have dealt with it in the "real-world". These open discussions could produce valuable insights that would be transferable to working with any target population differing from those related to one's individual background and experiences.

In summary, ongoing efforts are needed to reduce the usage of culturally insensitive imagery in the area of sport. However, these changes should not only occur solely as a result of governmental, or institutional, mandates, they should also be supported through learning activities that allow undergraduate students to gain a more open and comprehensive appreciation of the overall issue. 


\section{References}

Bacca, L. R. (2004). Native Images in Schools and the Racially Hostile Environment. Journal of Sport and Social Issues, 28 (1), 71-78.

Daniels, E.A. (2009). Sex Objects, Athletes, and Sexy Athletes: How Media Representations of Women Athletes Can Impact Adolescent Girls and College Women. Journal of Adolescent Research, 24 (4), 399-422.

Farnell, B. (2004). The Fancy Dance of Racializing Discourse. Journal of Sport and Social Issues, 28 (1), 30-53.

King, C. R. (2004). This is Not an Indian. Journal of Sport and Social Issues, 28 (1), 310.

Neville, H.A., Yeung, J.G., Todd, N.R., Spanierman, L.B., \& Reed, T.D. (2011). Color Blind Racial Ideology and Beliefs About a Racialized University Mascot. Journal of Diversity in Higher Education, 4 (4), 236-249.

Newman, J.I. (2007). Army of Whiteness? Colonel Reb and the Sporting South's Cultural and Corporate Symbolic. Journal of Sport and Social Issues, 31 (4), 315-339.

Staurowsky, E.J. (2007). You Know, We Are All Indian: Exploring White Power and Privilege in Reactions to the NCAA Native American Mascot Policy. Journal of Sport and Social Issues, 31 (1), 61-76.

Steinfeldt, J.A., Kaladow, J.K., Pagano, L.A., \& Steinfeldt, M.C. (2010). Racism in the Electronic Age: Rolde of Online Forums in Expressing Racial Attitudes about American Indians. Cultural Diversity and Ethnic Minority Psychology, 16 (3), 362-371.

Steinfeldt, J.A., \& Wong, Y.J. (2010). Multicultural Training on American Indian Issues: Testing the Effectiveness of an Intervention to Change Attitudes toward NativeThemed Mascots. Cultural Diversity and Ethnic Minority Psychology, 16 (2), 110-115. 
The Journal of SPORT, 2015, 4(2), 12-25 @ Kent State University

\title{
Creation and Instruction of a Coach-Implemented Mental Periodization Plan
}

\author{
Joe Stonecypher \\ Ball State University \\ Brianna Leitzelar \\ Ball State University \\ Lawrence W. Judge \\ Ball State University
}

\begin{abstract}
Periodization is defined as "the division of the annual plan to ensure an optimal performance for the main competition” (Bompa, 1999, p. 194). Periodization is an effective framework for physical training and often results in better performance outcomes (Gamble, 2006; Stone et al., 2000). Many researchers have proposed that extending the concept of periodization to mental skills training may be beneficial and has been shown in one study to help athletes improve their sport confidence and lower their sport trait anxiety (Guenthner et al., 2010). Sport psychology consultants can help coaches learn how to construct a mental periodization program, help coaches foster the sense of "flow" in their athletes, increasing their potential for peak performance. In an effort to more fully understand the framework needed to teach coaches how to design and implement a mental periodization plan, this paper will propose a specific example in which a high school softball coach designs and implements a mental periodization plan with his pitchers.

Key Words: Athlete performance, self-confidence, purposeful focus
\end{abstract}


Coaches and athletes often refer to the phenomenon of effortless performing at a peak level as "being in the zone." Sport psychology consultants refer to this optimal mindset as a flow state. It is the ultimate goal for any athlete in any type of sport competition. Often times, an athlete's desire to reach this state of mind may cause the athlete to focus their thoughts on achieving flow, causing distractibility which actually may prevent achieving flow (Judge et al, 2010). Therefore, it is believed that daily implementation of consistent processes, in both practice and competition, may increase the likelihood that an athlete reaches optimal focus resulting in a state of flow (Holliday, Burton, Sun, Hammermeister, Naylor, \& Freigang, 2008; Judge et al., 2010; Reardon, 1992).

This paper provides a description of periodization and the benefits for its use in developing a sport psychology program. The concepts are applied to an example of a group of high school softball pitchers in order to demonstrate how readers may take these concepts and apply them to their practice. The example located at the end of the paper will offer a hypothetical example of how to extend these concepts into practice.

\section{Periodization}

Periodization is defined by Bompa (1999) as "the division of the annual plan to ensure an optimal performance for the main competition” (pg. 194). Periodization plans are typically designed to include long-, moderate-, and short-term training cycles; macrocycles, mesocyles, and microcycles respectively, with the primary outcome goal to maximize training effects over time and to peak at the desired times (Kraemer \& Bush, 1998). Long-term training cycles (macrocycles) may vary in length from a few months (e.g., a college football season) to several years (e.g., an Olympic quadrennium). These long-term cycles are typically further divided into two or more moderate length training phases (mesocycles) that can range in length from a number of weeks to a year with the goal to reach peak performance at a specifically determined competition (e.g. World Championships, conference tournament). Finally, each mesocycle is usually comprised of four individual short-term cycles or phases (microcycles) that range from a couple weeks to a month long. A standard periodized training mesocycle consists of a sequence of four microcycles, preparatory, competitive, peaking, and recovery, with the length of each phase dictated by training objectives, athletes' needs, and the amount of time available between peaking for events (Holliday et al, 2008).

The central theme of individualized cycle development is critical to the success of periodization, both physically and mentally, because each athlete possess various strengths, weaknesses, goals, and schedules (Kraemer \& Bush, 1998). For example, a wrestler who is lacking aerobic stamina and consistent skill execution may decide to lengthen his preparatory phase to acquire the necessary skills and stamina prior to entering into his competitive phase. On the other hand, a collegiate distance runner struggling with shin splints may choose to modify his periodization plan through increasing the frequency and length of the recovery phases (Holliday et al, 2008). Cycles 
of a periodization program must also accommodate the requirements and structure of the athlete's sport. Holliday et al. (2008) stated that

an Olympic thrower might develop a four-year macrocycle, with mesocycles geared toward peaking each year for the NCAA and World Championships, whereas a professional tennis player would use a year-long macrocycle divided into four mesocycles, each leading up to one of the Grand Slam events. (p. 203). Ultimately, periodization planning is best utilized when it is designed to consider individual needs, maximize individual development and the timing needed to reach peak performance for major competitions (Holliday et al., 2008).

There are many studies that conclude the beneficial effects of periodization on differential training outcomes (e.g., Gamble, 2006; Stone et al., 2000). In a group of college-aged men, those who participated in a periodization based training program experienced higher gains on a 1RM Squat test than those who were not. Further, in a critical review, Fleck (1999) concluded that using a periodized framework is a superior strategy to train for peak performance. Turner (2011) agreed in a more recent review stating, " periodization represents an optimal strategy for organizing [strength and conditioning] programs” (pp. 44). Therefore it is recommended by many researchers that coaches use a periodized framework for physical training.

\section{Mental Periodization}

Recently, the idea that formatting skills training programs as periodized has been proposed (e.g., Balague, 2000; Blumenstein, Lidor, \& Tenenbaum, 2005; ) Although the majority of these papers are conceptual in nature, one case study indicated that a periodized mental skills training program may be effective (Guenthner, Hammermeister, Burton, \& Keller, 2010). The authors reported that the athletes involved in this program learned the mental skills, felt more confident, and felt less anxious in general after the mental skills training program.

Holliday et al. (2008) discussed the numerous problems that are often associated with attempting to implement a mental skills training program. One of the barriers may be connected with the abstract skill set that is required when teaching and learning through a mental skills training program. The notion of teaching mental skills is often met with reluctance from the athletes, as it is a skill set that is much more abstract than the physical training to which they are accustomed. Another barrier may be connected to frequency and duration of time spent with the athlete. Sport psychology consultants may have limited and inconsistent access to the athlete which may reduce the impact of mental skills training. This limited exposure and contact with the athlete may create a barrier due to reduced opportunity for the consultant to earn the athletes' trust, which may also affect the athletes' level of devotion to practice newly learned mental training skills (Holliday et al, 2008).

In addition to the recognized barriers to implementation of a mental skills program, doubts have also risen regarding the effectiveness of such programs. The 
effectiveness of the program's ability to promote consistent skills transfer to a competitive situation, minimize performance slumps, prevent boredom, avoid burnout, and contribute to an athlete's long-term development have all been called into question (Holliday et al, 2008).

However, the implementation method of periodization seeks to address these issues by creatively and systemically cycling the structure and delivery of mental skills training. Historically, the training of physical and mental skills has been provided separately when working with teams and individual athletes alike. Periodization has been used for decades to train athletes physically and technically and has been utilized predominately in the individual sport arena. Mental skills training, on the other hand, is typically considered only after the physical and technical training has been established. Because of this, seeking the support from sport psychology consultants is generally initiated only after an issue develops with an athlete.

\section{Training the Coach}

Training coaches to use a periodized mental training program may be an effective way to impart psychological skills training to their athletes. As mentioned previously, sport and exercise psychology consultants may experience barriers, such as an inability to gain the athletes' trust, which make it difficult to train their minds (Holliday et al., 2008). Additionally, training coaches to implement a periodized mental training program may help bring the need for sport psychology to the forefront of their minds. That way, the athletes can have all the physical and mental tools at their disposal that they need to reach the "flow" state. Lastly, training coaches in this matter may help foster a consistency with mental training that seems to be a factor in helping athletes achieve "flow."

Coaches are proficient in training the necessary sport skills and physiological systems along with the tactics associated with their sport. However, many coaches lack the knowledge or a proper framework for addressing the psychological components that are also necessary for success in sport (Judge et al., 2010). Coaches seeking success cannot limit their knowledge base to the physical side of training. Sport psychology has emerged in recent years as the latest tool for helping coaches prepare athletes to perform at the highest level; however, few coaches take full advantage of psychological skills preparation (Judge et al., 2010). The issue though is that high school athletic programs rarely have the funds and resources to hire an AASP-certified consultant in sport psychology to work long-term with their athletes. Therefore, the implementation of a psychological skills training (PST) program often falls to the head coach and staff who have little experience or knowledge of PST. It is for this reason that purposeful training specifically with the coach regarding how to design, as well as implement, their own PST program is the next logical step in sport psychology consulting. Through helping the coach learn how to construct a mental periodization program and how to teach the necessary PST skills to their athletes, a sport psychology consultant can pass on their knowledge to the coach. Teaching the coach may be the most efficient pathway to reach 
the athletes because the coach already has solid rapport and trust with the athletes, greater awareness of athlete's needs, and a deeper understanding of their specific sport and the associated pressures. In an effort to more fully understand the framework needed to teach coaches how to design and implement a mental periodization plan, this paper will investigate a specific case in which a high school softball coach works with the first author, a graduate student in sport psychology, to design and implement a mental periodization plan with his pitchers.

\section{Designed Mental Periodization Plan for Softball Pitchers}

It has been proposed that progress of periodized mental training cycles begins with education and acquisition of mental training skills and extends to practice, automation, implementation, and performance (Judge et al., 2010). Within each intermediate mesocycle, mental training skills and plans are first taught to the athletes during their recovery and preparatory phases. The skills are then practiced until they become automated during both the preparatory and competitive phases. Finally, the PST skills are integrated into the athletes' game and consistently performed during the competitive phase in an effort to achieve optimal performance during the specific peaking events (Judge et al., 2010).

Furthermore, mental training programs need to be designed based on the athletes' needs, while allowing more time for athletes that may be struggling to grasp the new mental training skill set. For example, effective imagery requires that the performer first master the essential skills vividness and controllability before imagery can be used to enhance sport performance. For example, a softball pitcher with poor imagery control may attempt to imagine the throwing of consistent strikes to the lower outside zone, but due to poor imaging control, the pitcher occasionally imagines throwing balls or giving up hits. In this case, the pitcher should limit the imagery practice to simple non-sport exercises until developing better imagery control. Basic PST skill acquisition and plan development must be the first priority when designing a periodized training program. The long-term development of an athlete through periodization is best understood as a dynamic and flexible process that must allow for adjustment based upon the individual athlete's differences in skill development (Judge et al., 2010). The data collected for this paper was obtained through the author's development of a plan which follows the model (see Table 1) set down by Judge and Gilreath (2011). The plan was implemented through a softball coach and was utilized with the team's pitchers. 
Table 1. Mental Periodization Model (Judge \& Gilreath, 2011).

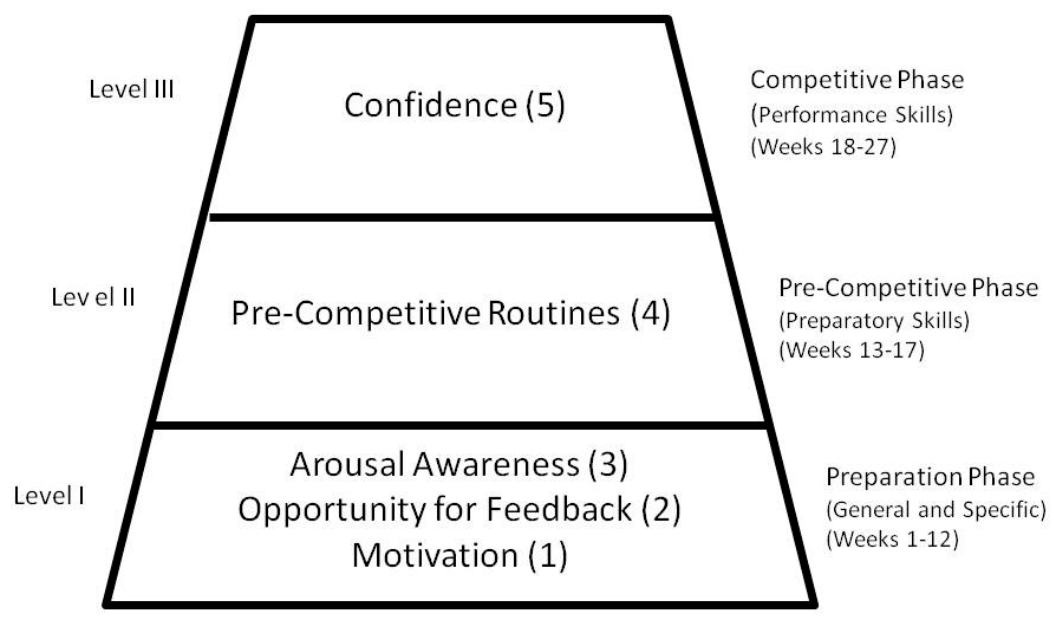

However, due to limitations related to the coach's prior knowledge, the age of the athletes, and the nature of performance for softball pitchers, the author constructed a simplified model that would address the athletes' most prominent needs while reducing the level of complexity for implementation (see Table 2). The author decided to focus on the skills of goal setting, pre-pitch routines, pre-game routines, and self-talk. The final three steps in the pyramid also included imagery. This allows individual athletes to incorporate imagery and self-talk into their routines through strategies that best met their individual needs. Each component will be discussed from this point forward. 
Table 2. Simplified Softball-Specific Model.

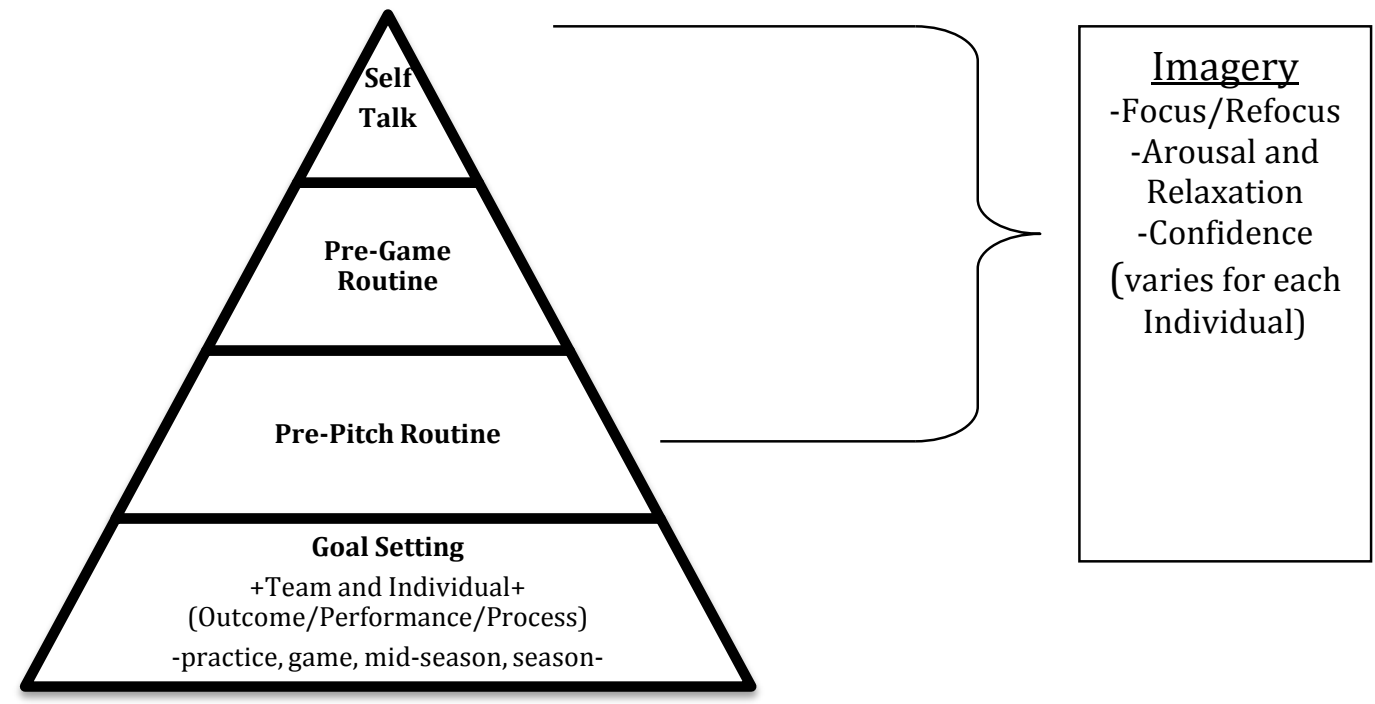

\section{Goal Setting}

Goal setting is one skill that is utilized by athletes and coaches across all sports and skill levels. However, the goals that are established are often times outcomeoriented, and achieving those lofty goals are not entirely under the control of the athletes. Examples of outcome-based goals include beating a specific opponent, having a certain win-loss record, or winning the big tournament. However, outcome goals can often cause anxiety for performers due to the high challenge and relatively uncontrollable nature of competition (Judge et al., 2010). However, there are other types of goals that can be implemented to help the athletes reach the outcome goal. Performance and process goals, the two types of "sub-goals", are more effective because they are based on components of which the athletes have a great sense of control. Process goals require athletes to establish small step challenges that build the athletic skill set to improve performance (e.g. I want 50 percent of my pitches in practice to be strikes) which may further the achievement of performance goals (e.g. I want to average 6 strikeouts a game). Both of these types of goals, in conjunction, can help the athlete work toward the outcome goal, while still having something concrete and achievable to build confidence (Judge et al., 2010).

An issue arises, however, when the nature of a process or performance goal are either too difficult or too easy, which can lead to anxiety or boredom (Judge \& Gilreath, 2011). Consistent feedback, tracking, and revision of an athlete's individual goal as well as team's goals must be provided. Czisentmihayi (1990) stated that feedback of execution must be present in order for flow to occur. This holds true for goal setting and tracking which allows the athletes to experience and see the progress toward their goals. 
Visualizing success and growth provides a basis for confidence to grow and gives the best opportunity for successful skill execution and optimal functioning (Judge et al., 2010).

\section{Pre-Pitch and Pre-Game Routines}

The creation, establishment, and maintenance of a pre-competitive routine are paramount for flow to occur. Research has shown that the establishment of a routine is effective for performance and the most effective means for athletes to focus on the task at hand and control arousal levels (Judge and Gilreath, 2011). For the plan being developed for the softball pitchers, a pre-pitch routine that focused on physical movements and imagery to refocus, visualize, and gain confidence as well as a pre-performance routine that centered on music selection and warm-up preparation were included.

\section{Self-Talk}

Cognitive psychology theory explained by Beck and Emery (1985) points out the powerful relationship between our thoughts, feelings, and behavior. Negative self-talk can pollute an athlete's confidence, making a situation even more difficult than it might otherwise appear (Judge \& Gilreath, 2011). Self-talk modification is one very effective way to correct thinking errors that hinder performance of an activity. However, it is notoriously difficult to teach athletes strategies which result in productive and engaging self-talk (Judge et al., 2010).

According to Reardon (1992), positive self-talk includes a focus on process variables, technical aspects of training and competing, rather than product or outcome, winning or losing. A focus on the present moment time dimension (what can I do, what am I doing now to enhance performance) rather than being distracted by future worrying (will I get a personal best, what if, etc.) or past failures (I should have, If only I had, etc.) is the goal for any athlete working to improve self-talk (Judge \& Gilreath, 2011). The methods of addressing self-talk with the softball coach were picked because of their simplicity and ease of implementation. A self-talk journal, reframing education, and selfconfidence statements with the other pitchers were picked as the techniques on which to focus.

\section{Imagery}

The final mental skill to be implemented with the softball pitchers was imagery. Imagery was chosen because it can be incorporated along with a variety of other mental skills and can be used to address several possible issues that an athlete may be facing (Holliday et al., 2008). The plan created for the softball pitchers included a specific use of imagery in the pre-pitch routines, the pre-game routines, and the self-talk skills in an effort to address issues surrounding focus, arousal control, and confidence. In imagining, athletes can draw on all senses: sound, sight, touch, taste, smell, and kinesthetic with an external focus (watching themselves from the audience) or internal focus (imagining as if 
they are actually performing) (Judge \& Gilreath, 2011). A study conducted by Smith, Wright, Allsopp, and Westhead (2007) looked at the effectiveness of the most prominent imagery model for replicating functional equivalence. To maximize this type of similarity, the PETTLEP model was developed. This model incorporates "Physical, Environment, Task, Timing, Learning, Emotion, and Perspective components" (Smith, Wright, Allsopp, \& Westhead, 2007, p. 80). Each of these aspects focuses on certain areas of the imaged scenario or the location and manner in which the image session is conducted. The effect of mental rehearsal appears to be that it provides a form of neuromuscular programming so that the performer is more likely to automatically behave in the preferred way during the actual performance (Judge \& Gilreath, 2011).

After the athlete has become proficient with the basic imagery skills, the coach can then implement a series of "what if" scenarios: unplanned competition situations that may include unforeseen obstacles like bad conditions, tough opponents, and minor mishaps during the pre-competitive phase so they are prepared for the "uncontrollables" that always accompany sport. This preparation works to help athletes respond appropriately during a competition when such situations arise (Judge et al., 2010).

\section{Training Cycles for Team Sports}

Up to this point, mental and physical periodization has been used most commonly with individual sports that allow athletes to peak for one or a few selected competitions each season. However, softball is a team sport with an extend season and several competitions within the season. The challenge is to adapt periodization when a consistently high level of performance is desired for an extended number of competitions that is standard with team sports (Holliday et al., 2008). To address this, the competitive and peaking phases are combined. Rather than working to improve performance systematically with peaks at desired times, team sport periodization seeks to build a stable performance plateau where team performance is consistently held at a moderately high level (Holliday et al., 2008).

In an example given by Holliday et al. (2008), the authors stated that when implementing a self-talk training program with high school cross-country runners, selftalk theory, benefits and limitations, and specific self-talk strategies should be introduced to the runners during the recovery phase. As the runners improve and progress through the preparatory phase (preseason), the self-talk skills are practiced, refined, and worked into competitive performance plans. By the time the runners begin their peaking phase (season), the essential self-talk skills such as " developing self-talk scripts, thoughtstopping, reframing self-defeating beliefs, and using race-specific self-talk cues have been highly automated, ensuring that such skills can be quickly and easily accessed when needed during the state championship meet" (Holliday et al., 2008, p. 206). 


\section{Softball Pitcher-Specific Plan}

The development of the softball pitcher-specific mental periodization plan began with the acquisition of the coach's year-long schedule, detailing when the pitchers worked directly with the coach, start date of school, other fall-sport engagements, and the official start of the preseason and regular season. Meetings with the coach were conducted to determine when specific skills would be introduced and maintenance of these skills would be evaluated. The following plan was developed based on the model by Judge \& Gilreath (2011). It was determined that goal-setting with the individual pitchers would take place at the start of the summer (off-season performance and process goals) and at the start of the preseason (pre-season performance and process goals/season outcome, performance, and process goals) with weekly meetings with the pitchers to track goal progress and make necessary revisions. The introduction of pre-pitch routines would be introduced in the summer with constant maintenance throughout the entire year. Pregame routine would not be implemented until the start of spring practice. Finally, selftalk skills and imagery skills would also be introduced and taught in the summer and fall with another second introduction in the start of the pre-season. This second introductory refresher would be followed by imaging of "what-if" exercises led by the coach to help in the building of mental toughness prior to and throughout the entirety of the regular season. All skills would be maintained and polished throughout the competitive phase of the regular season. See Table 3 for the mental skill periodization plan. 
Table 3:

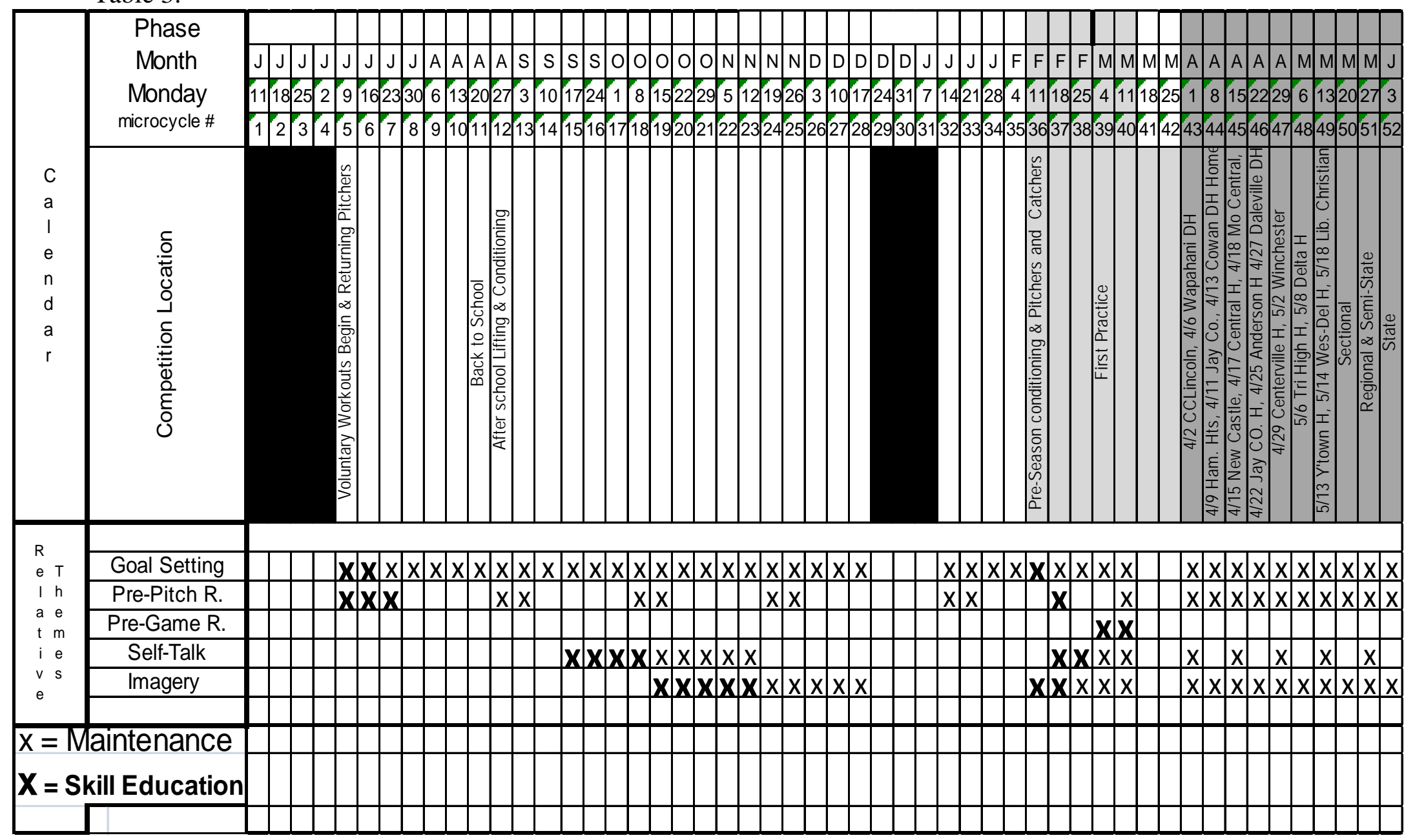


Instruction of the coach by the sport psychology consultant would be completed with inperson instructional conversations, hard-copy documents, and presentation tools that the coach can also provide to his athletes. The coach this hypothetical plan is designed for would have previous but limited experience with sport psychology, having taken masterslevel coaching courses which included mental skills training. The authors hold high hopes for potential success with the developed mental periodization program due to its basis in literature that indicates the effectiveness of periodization. Anticipated success is expected through the delivery of a wide-array of options and presentation material resources, keeping open the lines of communication between coach and consultant, and keeping the content for the athletes as streamlined and concrete as possible.

\section{Conclusion}

Athletes experience extremely high levels of stress, expectations, and physical challenges. Coaches often employ training programs that focus too heavily on physical training. Poor mental preparation can easily overcome and undermine a well-designed physical/technical preparation. All sports can benefit from development of a psychological training plan that is sequenced and unfolds harmoniously with the physical training plan. That gap between the science used to develop the training program and the art of execution (maximizing the performance on the playing and practice field) separates good coaches from great coaches. All coaches attempt to have their athletes perform in an uninhibited, relaxed, skillful manner. Introducing a periodized plan to develop the psychological skills along with the physical abilities during the year will take the conjecture out helping athletes perform at their best when it counts the most. 


\section{References}

Balague, G. (2000). Periodization of pyschological skills training. Journal of Science and Medicine in Sport, 3(3), 230-237.

Bandura, A. (1977). Self-efficacy: Toward a unifying theory of behavioral change. Psychological Review, 84, 191-215.

Beck, A., and Emery, G. (1985). Anxiety Disorders and Phobias: A Cognitive Perspective. New York: Basic Books.

Blumenstein, B., Lidor, R., \& Tenenbaum, G. (2005). Periodization and planning of psychological preparation in elite combat sport programs: The case of judo. International Journal of Sport and Exercise Psychology, 3(1), 7-25.

Bompa, T. (1999). Periodization: Theory and Methodology of Training. Champaign, IL: Human Kinetics.

Csikszentmihalyi, M. (1990). Flow: The psychology of optimal experience. New York: Harper \& Row.

Fleck S. Periodized strength training: A critical review. J Strength Cond Res 13:82-89, 1999.

Gamble, P. (2006). Periodization of Training for Team Sports Athletes. Strength \& Conditioning Journal, 28(5), 56-66.

Holliday, B., Burton, D., Sun, G., Hammermeister, J., Naylor, S., \& Freigang, D. (2008). Building the better mental training mousetrap: Is periodization a more systematic approach to promoting performance excellence? Journal of Applied Sport Psychology, 20(2), 199-219.

Judge, L. W. \& Gilreath, E. (2011). A Mental Plan. Techniques, 5(1), 24-34.

Judge, L. W., Bell, R. J., Bellar, D., \& Wanless, E. (2010). Developing a mental game plan: Mental periodization for achieving a "flow state" for the track and field throws athlete. The Sport Journal, 13(4).

Kraemer, W. J., \& Bush, J. A. (1998). Factors affecting the acute neuromuscular responses to resistance exercise. ACSM's resource manual: Guidelines for exercise testing and prescription (pp. 164-181). Baltimore: Williams \& Wilkins.

Lamb, M., \& Judge, L. W. (2012). Building self-confidence: Implementing a psychological skills training program. Indiana AHPERD, 41(3), 16-21.

Reardon, J., (1992). Incorporating Mental Skills into Workouts: Learning How to "Go with the Flow". American Athletics, 3, 54-55.

Ryba, T. V., Stambulova, N. B., \& Wrisberg, C. A. (2005). The Russian origins of sport psychology: A translation of an early work of A.C. Puni. Journal of Applied Sport Psychology, 17, 157-169.

Ryba, T. V., Stambulova, N. B., \& Wrisberg, C. A. (2009). Forward to the past: Puni's model of volitional preparation in sport . International Journal of Sport and Exercise Psychology, 7(3), 275-291. 
Smith, D., Wright, C., Allsopp, A., \& Westhead, H. (2007). It's all in the mind: Pettlepbased imagery and sports performance. Journal of applied sport psychology , 19(1), 80-92. doi: 10.1080/10413200600944132

Stambulova, N. B., Ryba, T. V., \& Wrisberg, C. A. (2006). A tale of two traditions in applied sport psychology: The heyday of Soviet sport and wake-up calls for North America. Journal of Applied Sport Psychology, 18, 173-184.

The Journal of SPORT, 2015, 4(1), 49-64 (C) Kent State University 
The Journal of SPORT, 2015, 4(2), 26-41 @ Kent State University

\title{
Understanding college females' intrinsic motives for physical activity: A qualitative comparison between athletes and non-athletes
}

\author{
Haley Cronon \\ Georgia Southern University \\ David Biber \\ Georgia State University \\ Daniel Czech \\ Georgia Southern University
}

\begin{abstract}
The purpose of the current research was to use a qualitative-methodological approach to understand attraction to physical activity in a sample of collegiate females. Attraction to physical activity, or motivation, can be grounded in the self-determination theory (SDT). Based on these results, the secondary purpose was to examine the similarities and differences between collegiate female athletes and non-athletes regarding attraction to physical activity. Participants included eight female athletes and eight female non-athletes. The interviews revealed two overarching themes: attraction and aversion to physical activity, each with subthemes. Understanding motives to engage in physical activity can help program planners create tailored interventions to improve overall exercise adherence. Clinical and collegiate relevance and limitations are discussed as are future research and program implementation suggestions.

KEYWORDS: Physical activity, intrinsic motivation, women, athlete, non-athlete
\end{abstract}


As cited by the Center for Disease Control (2013), regular physical activity has been shown to result in a multitude of health benefits for both men and women, including a decreased risk of cardiovascular disease, colon cancer, and obesity, as well as improvement in mood and well-being. Despite these findings, only $22 \%$ of adults regularly engage in sustained physical activity during leisure time, with males participating more than females (US Department of Health and Human Services, 1996). Ogden at al. (2012) indicate the rising rates of obesity, with over one-third of men and women aged twenty and over obese.

Regarding physical activity in women, Woitas-Ślubowska (2007) found that longterm involvement in competitive sports positively influences women's long-term physical activity decisions. This could be due to the tendency of women in sports to view physical activity as intrinsically rewarding and therefore enjoyable (Goncalves, Carvalho, \& Light, 2011; Kilpatrick et al., 2005). However, there are gaps in research examining the relationship between female sport participation and attraction to physical activity, especially within the collegiate female population. Previous studies on the motives of collegiate females' participation in physical activity have generally used questionnaires or surveys rather than the rich, descriptive data from qualitative-methodological or even mixed-methodological approaches (Henry et al., 2011; Pacheco et al., 2012). Furthermore, these studies have typically grouped participants by fixed lifestyle factors such as sex or age instead of changeable lifestyle factors like sports participation. Studies that have taken athletic affiliation into account have preferred to compare the motives of female athletes to the motives of their male counterparts rather than to their female, nonathlete counterparts (Cremades et al., 2012; LaChausse, 2006; Monzami et al., 2012). It is important to understand the motives of female athletes and non-athletes so that physical activity and sport training programs can be tailored to the needs and desires of the individuals.

The self-determination theory (SDT) is a multidimensional theory that focuses on intrinsic and extrinsic motivation and the role each play in determining behavior, such as physical activity (Deci \& Ryan, 1985). This theory suggests that individuals, including athletes, will be intrinsically motivated to engage in an activity, and therefore more likely to adhere in the activity, when three basic human needs are fulfilled: competence, autonomy, and relatedness (Deci \& Ryan, 1985; Vlachopoulos \& Michailidou, 2006). Competence refers to an individual's desire to interact effectively with their environment. Autonomy is the feeling of choice or control regarding activity, like exercise. Relatedness is an individual's feeling of connectedness to others while engaging in a certain activity (Ryan \& Deci, 2000). Therefore, understanding conditions that facilitate versus impede the fulfillment of these three factors in physical activity may prove efficacious in understanding physical activity and adherence. Increasing physical activity levels of nonathletes and athletes following the end of their collegiate careers is crucial in creating a lasting lifestyle centered around physical activity and healthy living (Cousins, 1998). 
Understanding the various intrinsic and extrinsic motives of women for participating in physical activity may play an important role in developing and increasing adherence to exercise programs, and decreasing the likelihood of a multitude of negative health consequences resulting from inactivity. As indicated by Mathes \& Battista (1985), because athletes may not be motivated by the same factors as non-athletes, it is important to understand the different reasons for participation in physical activity.

The purpose of the current research was to use a qualitative-methodological approach to examine attraction to physical activity of a sample of collegiate females via individual interviews. Based on these results, the secondary purpose was to compare the physical activity motives of female athletes and non-athletes within the collegiate sample.

\section{Participants}

\section{Methods}

Participants included eight female participants enrolled as full-time students currently participating in at least one sport, including NCAA Division I university, club, recreational, and intramural sports, and eight female participants with no current athletic affiliation. The number of participants was decided based on time constraints, convenience, and saturation, which is the point at which information from one more participant adds no new meaning (Marshall, 1996). All participants were full-time students at a southeastern university and at least 18 years of age.

\section{Procedure}

Following institutional review board approval, the investigator contacted multiple female athletes and non-athletes via email and in person with the intent of explaining the purpose of the study in detail. All prospective participants received informed consent forms and a demographic survey. Participants were informed that their participation was completely voluntary, that they could withdraw from the study at any point, and that all personal information would be kept strictly confidential. The demographic survey helped to determine whether participants met inclusion criteria as collegiate athletes or nonathletes.

After consent was received from each participant and the demographic survey had been completed, individual interviews were conducted with the participants at times mutually agreed upon by the investigator and participants. Interviews consisted of openended questions derived from the Children's Attraction to Physical Activity (CAPA; Brustad, 1993) assessment, the most reliable and convenient assessment that has been used in previous, related research (Biber et al., 2013). Each participant sat in a quiet classroom and was reminded that participation in the study was completely voluntary. Participants were told that they did not have to answer a question if they didn't want and could leave the classroom if they felt uncomfortable. The participants were asked to respond to each open-ended question as honestly and openly as possible and were given the opportunity to speak until they had fully responded to each question or statement. For 
the semi-structured individual interviews, eight open-ended, unbiased, non-threatening statements or questions were asked of each participant. Each interview was recorded with an iPhone using Phillips Dictation Recorder for later transcription. After completing the interview, each participant was allowed to ask questions and be further debriefed. Each interview lasted for approximately ten minutes.

\section{Data Analysis}

All interviews were processed according to a four-step method outlined by Czech et al. (2004) and Patton (2002). First, transcription allowed for repetitive reading of the interviews in order to obtain a full understanding of what was said. The text was then cleared, which involved analyzing the data in direct relation to the question at hand. During phenomenological reduction, all irrelevant, repetitive, or overlapping information was removed. This helped enhance readability and understanding. The transcripts were then verified by the research team to ensure the intended meanings were maintained. The data was placed into meaningful categories and different themes were identified based on repeated analysis of the categories and their meanings (Patton, 2002). Each theme was created to accurately and concisely convey the data collected in a meaningful fashion. It was necessary to use a balance of direct quotations and interpretation of the interviews to provide concise and accurate meaning (Patton, 2002).

\section{Reliability and Validity}

In qualitative research, data is considered reliable if it provides an honest interpretation and can be trusted as conveying the participant's intentions. With existential phenomenological research, the participant is viewed as an expert in the given topic of study and therefore viewed as trustworthy (Patton, 2002). If the information obtained is an accurate description of what actually happened according to the participant, then it can be considered reliable. Validity was ensured through the reduction of researcher bias via triangulation. Triangulation methods included a bracketing interview, member checking, and expert checking. An interview was conducted in which the open-ended questions were asked for the primary researcher and the responses thematized. The researcher's bias of intrinsic and extrinsic motivation and aversion to engage in were identified. The researcher's bias was identified and preconceived thoughts and beliefs regarding the topic at hand were attempted to be withheld (Czech et al., 2004). Expert checking helped minimize primary researcher bias in conjunction with the bracketing interview.

\section{Results}

The transcripts were first thematized without the lens of athlete or non-athlete. More than half, or nine out of sixteen of the participants had to have mentioned a topic for thematization. Next, athlete and non-athlete themes were distinguished. More than half, or five out of eight, of the athletes had to have mentioned a topic for thematization, 
and the same standard applied to non-athletes. Based on the transcriptions, all of the responses were thematized into attraction and aversion to physical activity. These two categories each contained subthemes.

Figure 1

\begin{tabular}{|c|c|c|}
\hline & Athletes & Nonathletes \\
\hline Attraction & $\begin{array}{ll}\text { - } & \text { Being Active } \\
\text { - } & \text { Body Image/Self Worth } \\
\text { - } & \text { Social Interaction and Support } \\
\text { - } & \text { Feeling Healthy/Good } \\
\text { - Advancement/Accomplishment } \\
\text { - }\end{array}$ & $\begin{array}{ll}\text { - } & \text { Being Active } \\
\text { - } & \text { Body Image/Self Worth } \\
\text { - } & \text { Social Interaction/Support } \\
\text { - } & \text { Feeling Healthy/Good } \\
\text { - } & \text { Advancement/Accomplishment }\end{array}$ \\
\hline Aversion & $\begin{array}{ll}\text { - } & \text { Incompetence } \\
\text { - } & \text { Pain or Injury }\end{array}$ & - Incompetence \\
\hline
\end{tabular}

Comparison of the physical activity themes between collegiate female athletes and nonathletes.

\section{Attraction to Physical Activity}

Every participant mentioned aspects that attracted them to physical activity. Six main themes emerged regarding attraction to physical activity: 1) Being Active 2) Feeling Healthy/Good, 3) Body Image/Self Worth, 4) Social Interaction and Support, 5) Advancement/Accomplishment, and 6) Enjoyment. Each attraction theme arose for both athletes and non-athletes aside from enjoyment, which was only evident in the athletes' sample.

\section{Theme 1) Being Active}

The most common theme to emerge regarding attraction to physical activity was being active. This theme emerged mainly in response to, "When you think about physical activity, what comes to mind?” Responses included moving, exerting energy, sweating, and working out.

"What comes to mind is just being able to move and be active and just being healthy, I guess, and being toned," (Non-athlete). A similar mentality was expressed by athletes as well. "Anything you do when you get up out of bed in the morning. Literally, like walking, running, jogging. Almost everything is an exercise when you think about it," (Athlete). 


\section{Theme 2) Body Image/Self Worth}

When asked how physical activity influences how participants feel about their appearance, they repeatedly mentioned feeling better about themselves after physical activity as well as improvements in their body image and/or general self-concept. "When I don't work out, I feel really fat and ugly, to be real honest, but when I do work out, it makes me feel better about my body image, even if it hasn't really changed,” (Athlete). Similar sentiments were expressed by non-athletes. "Body Image. It's pretty shallow, but you want to look your best. I'm not trying to show off to people, I'm trying to look my best for myself, which I think is a really big deal,” (Non-athlete).

\section{Theme 3) Social Interaction and Support}

The third most common theme to emerge regarding attraction to physical activity involved social interaction with peers, teammates, and friends, and social support from family and friends. These themes emerged mainly in response to the question, "How do your friends and family influence your choice of physical activities?” Friends, family, isolation, and peer approval were all reasons cited for physical activity engagement.

Well, I mean, my friends have always been active, just growing up, and all of the teams I've been on. So, you know, even if they stopped playing a sport, and I stayed in touch with them. I guess the way all my friends were, you know, your roommate's active even when they're not participating in a sport, so it's just one of those things where if you're hanging out with people who are active. And also I guess my family is. My parents always encouraged me to be in sports, be active. They've always been active, so it's just kind of like being around it has rubbed off on me and without even thinking about it now it's just a part of who I am (Athlete).

This non-athlete expressed not wanting to be alone as a reason for exercising. "That's the hardest thing I think for college students is that they don't want to do anything by themselves," (Non-athlete).

\section{Theme 4) Feeling Healthy/Good}

When asked what motivates them to exercise as well as when responding to the majority of the remaining questions, participants mentioned feeling healthy as an attractor to physical activity. Even if health was not directly stated as a motivator, a general recognition of the possible positive effects on one's body or mind were mentioned. This can be seen in quotes by athletes and non-athletes. "Well, one, it's a stress reliever, and it's a break from school, and it takes my mind off things, plus it keeps me in shape..." (Athlete). "I guess just being healthy in general... It's not really as much about what I look like but how I feel," (Non-athlete). 


\section{Theme 5) Advancement/Accomplishment}

When asked how they felt when trying a novel physical activity, the participants generally responded with eagerness to learn something new. “... But afterwards you feel good because you learned a new thing, and it just makes you feel awesome,” (Nonathlete). "Whenever I try a new physical activity, initially I feel... I anticipate it, I look forward to it, I'm excited to try something new, and I wonder if I'm going to be able to surprise myself and find out that I'm actually good at it or actually really enjoy it," (Female Athlete). Regarding motivation to exercise, accomplishment appealed to some participants. Competition was generally mentioned in regards to competing with one's self rather than with others. "Something that motivates me to exercise is having a long term goal to work for, so like a big running race for me, so that I can complete it. I did a marathon this year, and that really got me up to making sure I didn't slack," (Athlete). This was also seen in non-athletes. "I also think it's cool to be able to compete with yourself, especially with weight lifting, to see how much you can improve, and realizing that you're lifting more than you were a month ago, and just knowing that you have that competition just with yourself," (Non-athlete).

\section{Theme 6) Enjoyment (Athletes Only)}

The last theme to arise was exclusively notable within the collegiate female athlete sample and related to genuinely taking pleasure in exercise itself. "For me, my most enjoyed physical activity is running, and that's because I get a runner's high from it. I enjoy the actual activity of it. I enjoy the burn, and I enjoy the benefits that come from it." Athletes expressed enjoyed the physical and mental components of their sport. "The thing that motivates me the most is knowing that it's what I love to do. I love the feeling you get, the high, the power, and just how it makes me feel."

\section{Aversion to Physical Activity}

Although the purpose of the study was to gain a deeper understanding as to what attracts collegiate female athletes and non-athletes to participate in physical activity, the interviews also provided insight as to why this sample may be averse to physical activity. All but two participants mentioned incompetence as a source of aversion to physical activity. One additional theme arose in the athletes' sample, which was pain or injury.

\section{Theme 1) Incompetence}

When asked to describe their least favorite physical activity experience, what they thought of when they considered barriers to exercise, or feelings when trying a new physical activity, almost all of the participants expressed fear of either failing at the activity or lacking the skills, qualities, or ability to do the activity properly as a detriment to exercise.

My least enjoyed physical activity is hard to say... probably swimming because I'm not good at it. That's another reason that I like running, is because I'm good 
at it and I excel at it. So, swimming, I find it very hard to breathe, and it freaks me out. I'm not good at it. It's something that I've never been trained at, and I would like to be better at it, so I might end up doing it, but I really don't like it,” (Athlete).

In addition, having others witness their incompetence and consequently feeling embarrassed was another barrier to exercise. "I guess just being embarrassed and not knowing what you're doing. You're just gonna try to play a sport that you don't know how to do, just kind of trying it, and then people judging you or not knowing that you're, like, “Oh, they don't know how to do it, so they shouldn't be doing it,” (Non-athlete).

\section{Theme 2) Pain or Injury (Athletes Only)}

When asked to describe least favorite physical activity experiences or barriers to exercise, athletes continually mentioned past injuries, current injuries, and the potential to become injured, as well as an aversion to pain or soreness. "I've been sitting out because I have back spasms a lot. I've been having problems with that, so that's the least fun... Pain. It's a very hard barrier, pain, and when to know to stop, and when is it just soreness or is this something that's serious?" Physical injury or pain was expressed multiple times by athletes. "I think about things that will keep you from exercising, so whether that be physically like you're injured, you cannot exercise, or you're sick, or you don't feel like exercising because of some physical thing."

\section{Discussion}

The results revealed six major themes indicating collegiate women's attraction to physical activity: 1) Being Active 2) Feeling Healthy/Good, 3) Body Image/Self Worth, 4) Social Interaction and Support, 5) Advancement/Accomplishment, and within the athletes sample only, 6) Enjoyment. The results also revealed themes that made physical activity aversive: 1) Incompetence, and within the athletes sample only, 2) Pain/Injury.

\section{Attraction to Physical Activity}

\section{Theme 1) Being Active}

Participants felt attracted to physical activity because they could feel their body moving and that they were being healthy by exercising. These women also showed a tendency to associate physical activity with running and, surprisingly, lifting weights. Research has shown that significant loading, like that which occurs when weight training or walking, can positively influence bone mineral density in girls (Nasim, 2010). Additionally, Depcik \& Williams (2004) found that weight training may be an effective treatment for body image disturbance, as participants who regularly lifted weights saw improvements in body image. With this in mind, it can be understood why some women may be attracted to weight training and running as sports or leisure-time activities. 
However, this study contributes to the minimal research has been done on this subject of female attraction to particular types of physical activity.

\section{Theme 2) Body Image/Self Worth}

Previous research supports the positive relationship between body image and female motivation to exercise (Depcik \& Williams, 2004; LaChausse, 2006; Egli et al., 2011). This study found improvements in self-concept after exercise to be a strong reason for participating in physical activity. Participants frequently mentioned feeling better about themselves, physically and in general, after exercising. As a female non-athlete put it, "Body Image. It's pretty shallow, but you want to look your best. I'm not trying to show off to people, I'm trying to look my best for myself, which I think is a really big deal.” Athlete and non-athlete participants associated physical inactivity with feeling fat, ugly, and bad about themselves, as they similarly associated exercising with feeling healthy, feeling good, and feeling good about themselves. Aside from obvious changes in physical appearance such as fat loss and muscle mass gain due to exercise, Fox and Corbin (1989) suggest that physical activity alone, without the influence of bodily changes, impacts our physical self-perceptions, such as perceived physical strength and conditioning. This, in turn, impacts our physical self-worth and global self-esteem. Females' attraction to physical activity due to improvements in body image and/or selfworth may be a necessary component to increase physical activity and adherence.

\section{Theme 3) Social Interaction and Support}

Participants were attracted to physical activity in which they were with friends who encouraged and supported them. Athletes and non-athletes not only derived enjoyment out of activities in which they were with their friends but were more likely to partake in certain activities if their friends were with them. One female non-athlete explained, “That's the hardest thing I think for college students is that they don't want to do anything by themselves." This suggested need for has been supported by previous research as well. In a study by VanKim and Nelson (2013), low socializing was associated with higher odds of poor mental health in college students. In addition, SmithRay and colleagues (2012) found social cohesion as a determining factor of attendance in exercise and nutrition programs for women of color. The self-determination theory emphasizes feelings of relatedness as important intrinsic motivators for physical activity and adherence (Deci \& Ryan, 1985). Regarding athletes specifically, team cohesion and perceived motivational climate have been found to be strongly positively associated (Horn et al., 2012). A meta-analysis of qualitative research regarding motives to engage in physical activity and sport found that support from family and significant others, developing social networks, and shared experiences were all described as attractive and enjoyable aspects of participation from youth through elderly (Allender, Cowburn, \& Foster, 2006). 


\section{Theme 4) Feeling Healthy/Good}

Participants reported feeling healthy or good after partaking in physical activity. Although participants acknowledged that they were generally tired directly after exerting energy, they agreed that they felt better long-term after exercising. Other studies have supported these results, finding that individuals who regularly exercised were less likely to report poor mental health and perceived stress and saw increases in health-related quality of life (Lerdal et al., 2013; VanKim \& Nelson, 2013).

\section{Theme 5) Advancement/Accomplishment}

Improving upon current skills or learning new skills can be linked to overall competence as a source of enjoyment in physical activity. Competence is part of a triad of necessities of the self-determination theory that contribute to intrinsic motivation to engage in and enjoyment in physical activity (Deci \& Ryan, 1985). Participants were highly attracted to activities in which they could learn new skills, even if they were initially uncomfortable with the activity: “... But afterwards you feel good because you learned a new thing, and it just makes you feel awesome," (Non-athlete). In addition, the participants frequently mentioned accomplishment as a source of motivation to exercise; however, competition was self-directed rather than with others. For example, one athlete was cited as saying, "Something that motivates me to exercise is having a long term goal to work for, so like a big running race for me, so that I can complete it," and one nonathlete stated, "I also think it's cool to be able to compete with yourself, especially with weight lifting, to see how much you can improve, and realizing that you're lifting more than you were a month ago, and just knowing that you have that competition just with yourself.” These results were surprising, as athletes have generally been reported to be far more competitive than their non-athlete counterparts (LaChausse, 2006). However, research has also found women to be far less likely than men to rate competition with others as a motivation to exercise (Mathes \& Battista, 1985).

\section{Theme 6) Enjoyment (Athletes Only)}

The last theme to arise was seen in the athletes sample only and related to feelings of enjoyment derived from sport as a form of physical activity. "The thing that motivates me the most is knowing that it's what I love to do. I love the feeling you get, the high, the power, and just how it makes me feel." The fact that this theme was not prevalent in the non-athlete's subgroup suggests that athletes are possibly more likely to enjoy exercise itself, rather than its rewards, than non-athletes. This motivation due to genuine pleasure derived from an activity rather than its external returns is the definition of intrinsic motivation (Deci \& Ryan, 1985). This is in line with previous research that suggests that athletes are more likely to engage in physical activity because of an inherent tendency to seek challenges and to push past their boundaries (Vallerand \& Losier, 1999). 


\section{Aversion to Physical Activity}

\section{Theme 1) Incompetence}

The self-determination theory emphasizes the need for competence in developing intrinsic motivation to engage and adhere to exercise and sport activity (Deci \& Ryan, 1985). This helps explain why the participants of the current study listed potential failure and the inability to successfully participate physical activity as aversive conditions of physical activity. "My least enjoyed physical activity is hard to say... Probably swimming because I'm not good at it. That's another reason that I like running, is because I'm good at it and I excel at it. So, swimming, I find it very hard to breathe, and it freaks me out. I'm not good at it. It's something that I've never been trained at, and I would like to be better at it, so I might end up doing it, but I really don't like it.” Research supports the SDT that a lack of competence hinders sport enjoyment (Davison, Schmalz, \& Downs, 2010).

\section{Theme 2) Pain or Injury (Athletes Only)}

A number of athletes mentioned certain injuries and aversion to pain as reasons for not wanting to participate in physical activity. "I've been sitting out because I have back spasms a lot. I've been having problems with that, so that's the least fun... Pain. It's a very hard barrier, pain, and when to know to stop, and when is it just soreness or is this something that's serious?” Research supports this theme of injury as an aversive factor to physical activity enjoyment (Biber et al., 2013). It is unclear from previous research why this theme was only apparent within the athlete's subgroup. As this theme typically related to current injuries or pain from current injuries, it could be deduced that this sample of athletes was possibly more susceptible to exercise-induced injury due to the greater number of days on average that they exercised per week.

\section{Limitations}

It was attempted to conduct the present research with minimal bias and external influence, but as with all research, certain limitations were inevitable. It is possible that certain responses during the individual interviews were due to social influence or pressure. Also, the study cannot be generalized to women athletes and non-athletes outside of the university setting. Future research could be conducted with various samples of women to increase the scope of aversion and attraction to physical activity. It could also be helpful to the specific subgroups of athletes, such as university, club, intramural, and/or recreational sports. Three of the participants currently participating in university athletics mentioned incentives as an attractor to physical activity and burnout as a barrier to physical activity. Understanding why athletes and non-athletes experience these increases in burnout, depression, anger, and fatigue during current or previous sport 
participation could help coaches and universities create a more enjoyable sport experience.

\section{Conclusions}

The present sample of collegiate women expressed various a multitudes of factors that contributed to their attraction and aversion to physical activity. With the rising rates of physical inactivity (Ogden et al., 2012), finding ways to improve the availability of enjoyable physical activity is essential. With female college students in particular, it is important to design physical activity programs with the expressed needs to feel confident, competent, and socially supported when engaging in physical activity in mind so as to cultivate intrinsic motivation and therefore adherence to exercise, as women tend to decrease their participation in physical activity as they age (Gonçalves et al., 2011). By understanding the themes related to aversion to physical activity, programs could attempt to minimize failure and injury so as to increase enjoyment. Student recreation centers could devise physical activity programs with an understanding of collegiate life, the need to balance schoolwork, occupation, and recreation, and a concentration of enjoyment aspects of intrinsic motivation. This study furthers the understanding regarding the motives of college females' engagement in physical activity. 


\section{References}

Allender, S., Coburn, G., \& Foster, C. (2006). Understanding participation in sport and physical activity among children and adults: A review of qualitative studies. Health Education Research, 21(6), 826-835. doi: 10.1093/her/cyl063

Biber, D. D., Czech, D. R., Harris, B. S., \& Melton, B. F. (2013). Attraction to physical activity of generation Z: A mixed methodological approach. Open Journal of Preventive Medicine, 3, 310-319. doi: 10.4236/ojpm.2013.33042

Brustad, R. J. (1993). Who will go out and play? Parental and psychological influences on children's attraction to physical activity. Human Kinetics Publishers, Inc., 5, 210-223.

Centers for Disease Control. Physical Activity and Health: The Benefits of Physical Activity. 2008. Centers for Disease Control: Atlanta.

Cousins, S. O. B. (1998). Exercise, aging, and health: Overcoming barriers to an active old age. Taylor \& Francis.

Cremades, J., Flournoy, B., \& Gomez, C. B. (2012). Scholarship status and gender differences in motivation among U. S. collegiate track and field athletes. International Journal of Sports Science \& Coaching, 7(2), 333-344. doi: 10.1260/1747-9541.7.2.333

Czech, D. C., Wrisberg, C. A., \& Fisher, L. A. (2004). The experience of Christian prayer in sport. Journal of Psychology and Christianity, 1(23), 3-11.

Davison, K. K., Schmalz, D. L., \& Downs, D. S. (2010). Hop, skip...no! Explaining adolescent girls' disinclination for physical activity. Annals of Behavioral Medicine, 39(3), 290-302. doi: 10.1007/s12160-010-9180-x

Deci, E. L., \& Ryan, R. M. (1985). Intrinsic motivation and self-determination in human behavior. New York, NY: Plenum Press.

Depcik, E. E., \& Williams, L. L. (2004). Weight training and body satisfaction of bodyimage-disturbed college women. Journal of Applied Sport Psychology, 16(3), 287-299. doi: 10.1080/10413200490498375

Egli, T., Bland, H. W., Melton, B. F., \& Czech, D. R. (2011). Influence of age, sex, and race on college students' exercise motivation of physical activity. Journal of American College Health, 59, 399-406. doi: 10.1080/07448481.2010.513074

Fox, K. R., \& Corbin, C. B. (1989). The physical self-perception profile: Development and preliminary validation. Journal of Sport and Exercise Psychology, 2, 408430.

Gonçalves, C. E., Carvalho, H., \& Light, R. (2011). Keeping women in sport: Positive experiences of six women's experiences growing up and staying with sport in Portugal. Asian Journal of Exercise \& Sports Science, 8(1), 39-52.

Henry, M., Sanborn, C. F., Senne, T. A., \& Nichols, D. L. (2011). Influences on exercise and sports participation in female college students. TAHPERD Journal, 79(2), 811. 
Horn, T., Byrd, M., Martin, E., \& Young, C. (2012). Perceived motivational climate and team cohesion in adolescent athletes. Sport Science Review, 21, 25-48. doi: 10.2478/v10237-012-0009-3

Kilpatrick, M., Hebert, E., \& Bartholomew, J. (2005). College students' motivation for physical activity: differentiating men's and women's motives for sport participation and exercise. Journal of American College Health, 54(2), 87-94.

LaChausse, R. G. (2006). Motives of Competitive and Non-Competitive Cyclists. Journal of Sport Behavior, 29(4), 304-314.

Lerdal, A., Hannevig Celius, E., \& Pedersen, G. (2013). Prescribed exercise: A prospective study of health-related quality of life and physical fitness among participants in an officially sponsored municipal physical training program. Journal of Physical Activity \& Health, 10(7), 1016-1023.

Lincoln, Y. S., \& Guba, E. G. Naturalistic Inquiry. Beverly Hills, Calif.: Sage, 1985a.

Lincoln, Y. S., \& Guba, E. G. (1986). But is it rigorous? Trustworthiness and authenticity in naturalistic evaluation. New directions for program evaluation, (30), 73-84.

Marshall, M. N. (1996). Sampling for qualitative research. Family practice, 13(6), 522526. doi: 10.1093/fampra/13.6.522

Mathes, S. A. \& Battista, R. (1985). College men's and women's motives for participation in physical activity. Perceptual and Motor Skills, 61, 719-726. doi: 10.2466/pms.1985.61.3.719

Nasim, H. (2010). The effect of short-term weight-bearing exercise on bone mass density in obese and thin young girls. Sport Scientific \& Practical Aspects, 7(2), 11-16.

Ogden, C. L., Carroll, M. D., Kit, B. K., \& Flegal, K. M. (2012). Prevalence of obesity in the United States, 2009-2010.

Pacheco, L., Mas, F., Olivarez, A., \& Avila, M. (2012). Motivational factors related to female participation in collegiate sports. Journal of Human Sport \& Exercise, 7(4), 783-793.

Patton, M. Q. (2002). Qualitative research and evaluation methods. Thousand Oaks, CA: Sage.

Ryan, R. M., \& Deci, E. L. (2000). Self-determination theory and the facilitation of intrinsic motivation, social development, and well-being. American psychologist, 55(1), 68. doi: 10.1037/0003-066X.55.1.68

Smith-Ray, R., Mama, S., Reese-Smith, J., Estabrooks, P., \& Lee, R. (2012). Improving participation rates for women of color in health research: the role of group cohesion. Prevention Science: The Official Journal of the Society For Prevention Research, 131, 27-35. doi: 10.1007/s11121-011-0241-6

US Department of Health and Human Services. (1996). Physical Activity and Health: A Report of the Surgeon General. Atlanta, GA: US Department of Health and Human Services, Centers for Disease Control and Prevention, National Center for Chronic Disease Prevention and Health Promotion. 
Vallerand, R. J., \& Losier, G. F. (1999). An integrative analysis of intrinsic and extrinsic motivation in sport. Journal of Applied Sport Psychology, 11, 142-169. doi: 10.1080/10413209908402956

VanKim, N. A., \& Nelson, T. F. (2013) Vigorous physical activity, mental health, perceived stress, and socializing among college students. American Journal of Health Promotion. 28(1), 7-15. doi: http://dx.doi.org/10.4278/ajhp.111101QUAN-395

Vlachopoulos, S. P., \& Michailidou, S. (2006). Development and initial validation of a measure of autonomy, competence, and relatedness in exercise: The basic psychological needs in exercise scale. Measurement in Physical Education and Exercise Science, 103, 179-201. doi: 10.1207/s15327841mpee1003_4

Woitas-Ślubowska, D. (2007). Practicing competitive sports at an earlier age as an important determinant of women's participation in physical recreation. Studies in Physical Culture \& Tourism, 14(2), 185-192. 
Table 1

\section{Appendix B}

\begin{tabular}{|l|l|}
\hline \multicolumn{2}{|c|}{ Semi-Structured Interview } \\
\hline Question 1 & $\begin{array}{l}\text { When you think about physical } \\
\text { activity, what comes to mind? } \\
\text { Describe your favorite physical } \\
\text { activity experience. }\end{array}$ \\
\hline Question 3 & $\begin{array}{l}\text { How does physical activity } \\
\text { influence how you feel about } \\
\text { your appearance? }\end{array}$ \\
\hline Question 4 & What motivates you to exercise? \\
\hline Question 5 & $\begin{array}{l}\text { How do your friends or family } \\
\text { influence your choice of physical } \\
\text { activities? }\end{array}$ \\
\hline Question 6 & $\begin{array}{l}\text { Describe how you feel when you } \\
\text { try a new physical activity. }\end{array}$ \\
\hline Question 7 & $\begin{array}{l}\text { Describe your least enjoyed } \\
\text { previous exercise experience. }\end{array}$ \\
\hline Question 8 & $\begin{array}{l}\text { When you think about barriers to } \\
\text { exercising, what comes to mind? }\end{array}$ \\
\hline
\end{tabular}

List of questions asked in the interview process. 
The Journal of SPORT, 2015, 4(2), 42-59 @ Kent State University

\title{
An Analysis of the Factors and Marketing Techniques Affecting Attendance at NCAA Division I Women's Basketball Games
}

\author{
David Martinson \\ Bowling Green State University \\ Ray Schneider \\ Bowling Green State University \\ Brian McCullough \\ Seattle University
}

\begin{abstract}
The gap in revenue production at most schools between the two "big-time college sports" and women's basketball is vast. One of the biggest contributors to revenue for most sports is attendance, and while there has been some general research on attendance in college sports, there is little prior work examining women's basketball specifically. The purpose of this study was to fill the dearth of research and to gather information on the factors that influence attendance at women's intercollegiate basketball games. Division I marketing directors at 329 schools that sponsored Division I women's basketball were included in the survey and 18 (35.87\%) participated. The discussion section examines the qualitative survey answers in detail and provides recommendations to those involved in in the industry of marketing women's college basketball.
\end{abstract}


The landscape of college athletics in America is continually changing, but over recent decades changes have primarily been motivated by money (Cooper, 2011), with the main revenue driving sports undoubtedly being football and men's basketball (Whiteside et al, 2011). The focus on increasing revenue has caused National Collegiate Athletic Association (NCAA) athletic departments to engage in a continuous battle of one-upmanship, specifically at the Division I level. This has led to vast increases in spending on the main revenue sports, and less focus on funding for the remaining nonrevenue sports (Cooper, 2011). Women's sports in particular are caught in a seemingly never-ending cycle in the quest for more popularity by way of increased exposure and subsequent increases in attendance. The sport media tend to cover intercollegiate men's sports such as football, basketball, and baseball, which leads to an increased fan base and, more importantly, an increase in revenue from gate receipts (Engleman et al, 2009). While women's sports are, in general, less popular than their male counterparts (Shackelford \& Greenwell, 2005), it is also undeniable that the number of females participating in intercollegiate athletics has increased rapidly over the past twenty-five years. In 2012, almost 200,000 females participated in NCAA sponsored sports (Wolverton, 2012).

Despite this growth, research focusing on attendance at female athletic contests, and women's basketball in particular, is very limited (Depken, Williams, \& Wilson, 2011). There has been a relatively large amount of work examining spectator attendance, but nearly all of this is devoted to male sports (Shackelford \& Greenwell, 2005). While helpful, this work is not directly applicable to women's sports. Researchers have shown that the attendance at men and women's college basketball games are very different. To this end, it is important to explore this polarization in attendance and the unique ways to market to the target audience of each specific sport (Shackelford \& Greenwell, 2005; Kahle, Duncan, Dalakas, \& Aiken, 2001; Ridinger \& Funk, 2006). While the main revenue generating sports receive the most marketing and promotion the goal of increasing revenue for an athletic department can also be enhanced by improving attendance and identification with less popular teams. Fink and colleagues found college athletic departments have two significant sources of untapped revenue: female fans and fans of women's basketball (Fink, Trail, \& Anderson, 2002). While this study focuses on women's basketball, female fans comprise a significant portion of that fan base thus making this study even more valuable within intercollegiate athletic marketing research. The more understanding there is about the factors that affect attendance for women's college basketball the more effectively these games can be promoted, which can in turn increase athletic department revenue and continue the growth of female athletics. Although there are numerous areas that could be studied related to marketing of women's sports, the purpose of this study was to examine the marketing of women's college basketball. The review of literature found below discusses marketing tendencies of sport in general. The focus of this research will be to enhance this research by examining the marketing of women's college basketball, an untapped market. 


\section{Review of Literature}

Although there is a dearth of research to solely review women's college basketball (Depken, Williams, \& Wilson, 2011), there is ample literature focusing on the motivators of attendance for fans at men's sports (Shackelford \& Greenwell, 2005). Even though it may not be directly generalizable to women's basketball, it provides a gap in the literature and the basis for research to close this gap. Research on sport spectator attendance has often examined the differences between male and female spectators (James \& Ridinger, 2002). One of the major differences noted in multiple studies examining fans of female athletics is a higher emphasis on the social atmosphere at games being a motivator for attendance (Fink et al., 2002; Ridinger \& Funk, 2006). Female fans look to be involved in a community that supports a team and attend games both to be with their friends and to create new relationships. Without someone to accompany them to games female fans were far more likely to stay home from sporting events (Trail \& Kyoum, 2011).

Much of the success of college athletics is based upon tradition (Wells, Southall, \& Peng, 2000). While women's sports do not have the same history as many male sports, simply due to their delayed start, tradition is an increasing factor in attendance at games. Tradition has been described as a motivator for all spectator segments at college sports (Wells et al., 2000). Female fans have shown an even stronger link to university pride as a motivator for their attendance at college sporting events than their male counterparts (Ridinger \& Funk, 2006).

An additional segment for analysis in this study is supported by research on the fans of the Women's National Basketball Association (WNBA). Although it is a professional league and thus there are many differences with NCAA women's basketball, some of the fans do cross over. Fans attending WNBA games often prefer to attend because of the perceived positive role model status of players and to support women's athletics (Fink et al., 2002). The perception of positive player image is not something that always carries over to the National Basketball Association (NBA) or other male professional leagues. Also many fans attend WNBA games simply to support the growth of women's athletics (Fink et al., 2002). In many ways, attending a professional game to support female sports is no different than a college alumnus or fan attending multiple sporting events to support their school. Other factors that have been shown as motivators for attending female athletic events include aesthetic quality, sense of satisfaction from victories, personal attachment to the team, and a positive atmosphere (Ridinger \& Funk, 2006; Wells et al., 2000). Women's basketball in particular is often noted as more aesthetically pleasing than the modern male game (James \& Ridinger, 2002).

It is important to recognize the impact that a successful team can have on increasing attendance. Winning creates excitement, increases media coverage, and gives a sense of satisfaction to spectators. All of these factors can lead to increased attendance. One specific measure of success that has been linked with attendance figures is home team winning percentage, which has been described as a strong predictor of attendance in 
multiple sports (Shackelford \& Greenwell, 2005; Whitney, 1998). This correlation has also been confirmed by other studies specifically in relation to intercollegiate athletics (DeSchriver, 1999; Wells et al., 2000).

Another measure of success is the overall success of the previous season.

Winning percentage from the previous year has been positively linked to attendance for women's basketball (Shackelford \& Greenwell, 2005). Post-season participation also has a significant impact on attendance the following season. Winning multiple games in the National Invitational Tournament (NIT) or participating in the NCAA Tournament has been shown to have a positive effect on attendance the next year. Winning either of these tournaments can also have a positive boost that lasts for multiple seasons (Depken et al., 2011). This line of research supports the necessity of fielding a winning team if attendance is a priority for any organization. Although there are many variables that influence winning, at the collegiate level a major factor in success is recruiting. To be effective throughout the recruiting process requires strong support from the athletic department as well as close integration with other school departments (Wells et al., 2000). Investment in this aspect of collegiate athletics cannot be discounted, as it lays the foundation for any future success. Athletic departments looking to cut costs may see some recruiting trips as an easy way to limit expenditures, but in context of the research showing the importance of winning this has a likelihood of being counterproductive.

While trailing the impact of success, several other factors have a correlation with attendance at college sporting events. Student enrollment has successfully predicted attendance at collegiate women's basketball, softball, and volleyball games (Shackelford \& Greenwell, 2005). In contrast, community size does not have a direct impact at the collegiate level, unlike major professional sports (Shackelford \& Greenwell, 2005). Competition is another important factor in attendance for college sports. Having multiple competing teams within a fifty-mile radius has shown a negative correlation with attendance figures (DeSchriver \& Jensen, 2002). Furthermore, for women's basketball, teams that play in large markets that feature three or more direct competitors have significantly lower attendance than those with a market to themselves (Shackelford \& Greenwell, 2005). Having one or more professional sports teams in the area is also a negative predictor for attendance (Shackelford \& Greenwell, 2005). This shows the effect that external factors can have on attendance, raising the importance of proper marketing efforts for schools in crowded markets. Another factor in attendance is ticket price. Women's basketball typically has lower ticket prices than that of football or men's basketball. Fink and colleagues (2002) have found this is a significant reason why fans of women's basketball attend multiple games.

When reviewing the research related to factors impacting attendance at sporting events, it is important to note that research not performed specifically on women's basketball may not be generalizable to this study. The findings have varied significantly between sport type, level of sport, and gender of the participants (Shackelford \& Greenwell, 2005). Therefore, research findings should only be considered applicable to 
the specific sport they investigate, as generalization between sports and genders may not be accurate. There is little research for professionals involved in the marketing of women's basketball to reference effectively when seeking to improve their attendance figures. The work of these employees is vital, as simply having a special promotion in place has been shown to increase spectator attendance (Wells et al., 2000). Any research related to women's basketball is dated as well as limited in scope. For example, spectators at women's basketball games have also been shown to be more responsive to promotions than fans of the male teams (Fink et al., 2002). However, there is no research to document what types of promotions are most effective.

While there are several sources one could query in an attempt to examine the effects of marketing efforts on attendance for women's Division I basketball, none are better than the athletic department employees directly responsible for these efforts. Having a position within a college athletic department that is specifically responsible for marketing athletics has a significant positive impact on attendance figures (Wells et al., 2000). This suggests that most marketing employees have an enhanced understanding on the promotions that both help and detract from attendance, at least at their schools' sporting events. Having this knowledge and understanding is a vital part of their job responsibilities, and a lack of implementing proper marketing strategies can eventually lead to dismissal from their employment. While men's sports often get the focus of college athletic marketers, it is still their responsibility to understand and promote women's sports at an affordable price both for the university and the spectators (Liebert, 2008). Based on these factors and the purpose of this study, it is apparent that the most effective people to study would be the employees within college athletic departments who are responsible for marketing women's basketball.

\section{Methods}

The purpose of this study was to examine the marketing factors that have the greatest effect on attendance at NCAA women's basketball games. Email communication was sent to the person responsible for marketing women's basketball at each of the 329 schools that sponsored a Division I women's basketball team. The employee to receive the email from each school was selected by job title. The most common job title found was director of marketing, but there was a wide range of specific titles including positions with a focus on external relations, corporate sales, or communications. Instrument

The survey included demographic questions including school, position, and experience. Questions related to the attendance goals and actual attendance figures at woman's basketball games for the past season were included in the survey. Respondents then were asked a series of questions measured using a 7-point Likert scale, with choices ranging from 1 or no impact to 7 or most impact. The rated questions consisted of external factors such as team performance, game scheduling, and ticket costs. The next series of Likert scale questions included a list of different marketing techniques, which 
the respondents were asked to rate on their perceived effectiveness. The list of marketing techniques was based on the information sought from NBA marketers in prior research (Dick \& Turner, 2007). The survey concluded with open-ended questions about specific promotions or marketing techniques that had been either very successful or very unsuccessful at the respondent's institution.

\section{Results}

A total of 119 survey responses were received out of a distribution list of 329 for an overall response rate of $35.9 \%$. The first quantitative questions presented to respondents included basic demographic data. Years of experience in athletic marketing gathered a wide range of responses $(M=6.3, S D=3.99)$. Participants were then asked about the number of years of current organizational tenure $(M=4.2, S D=4.65)$.

Addressing the topic of women's basketball more specifically, the next questions dealt with attendance at games during the 2011-12 season. The first attendance question asked if each school had met their attendance goal for the season. Only 41.18\% $(N=49)$ of participants answered that they had met their attendance goals, leaving 58.82\% ( $N=$ 70) that had a lower attendance than they anticipated. The subjects were asked to list their average attendance for the year. Given the wide range of schools in this study there was predictably a wide range of attendance figures. The average attendance was ( $M=$ $1,458.4, S D=1,789.6$ ). Several outliers whose figures were around 10,000 per game skewed the data from the actual attendance of the sample.

The next series of questions focused on the impact of different types of external factors on attendance at women's basketball games. In this case, external factors are used to describe things that affect attendance, which are largely out of the control of marketing employees. Respondents were asked to rate each factor on a scale of one to seven, with one being not important and seven meaning the factor is extremely influential on attendance. Demographic information on the surrounding area was the first set of questions on external factors. There were seven factors to be considered in this section: proximity to other Division I schools, proximity to professional sports teams, general basketball knowledge of surrounding area, socioeconomic status of surrounding area, population size of surrounding area, student enrollment, and generosity of alumni and/or boosters. Of the factors, generosity of alumni and/or boosters scored the highest $(M=$ $4.10, S D=1.65$ ). Population size of the surrounding area was also noted as important, $(M=3.85, S D=1.68)$, and socioeconomic status was third $(M=3.82, S D=1.58)$. The least important factors were student enrollment $(M=3.50, S D=1.8)$ and proximity to professional sports teams $(M=3.37, S D=2.13)$; however, these factors also had a higher standard deviation than the other factors, indicating less of a consensus on their impact.

The next group of external factors related to team performance, which is outside the control of a marketing employee. The factors examined included number of in-state players, star players on roster, record during current season, team standing in conference, and record during previous season. There was a wider spread in mean scores for this 
section than the previous demographic section, but scores were significantly higher as well, showing the emphasis success can have on increasing attendance. The highest rated factor in this category was record during current season $(M=5.38, S D=1.49)$. Not only was current record the highest scoring factor in this section, but it also had the highest mean of all external factors. Team standing in conference was second $(M=5.01, S D=$ 1.63). While the team's record during the previous season was also important ranking third $(M=4.84, S D=1.69)$. The lowest score $(M=3.97, S D=1.88)$ belonged to number of in-state players on the roster. Another highly ranked effect on attendance y was single game specifics. This involved factors related to scheduling, such as game time either evening or afternoon, rivalry with opponent, ranking of opponent, and point in the season. Rivalry with opponent was listed as the most important factor $(M=5.14, S D$ $=1.54$ ), placing it as the second highest rated factor in all categories. Evening game time was the second most important single game factor $(M=5.08, S D=1.43)$. Point in season was the least important in this section $(M=4.25, S D=1.51)$. The standard deviations of all the factors in the single game category were also relatively low so combining this with the general high ratings scores shows that as a group marketing employees see game time and date as vital to improving and sustaining attendance.

The final section on external factors, cost and ease of attendance was the lowest scoring of all categories. One possible conclusion is that ticket prices for women's basketball games are already relatively low, especially compared to men's sports and professional games, therefore it is not a differentiating factor in deciding whether to attend. This category featured five factors: ticket price, parking costs, ease of parking, arena accessibility, and total cost of attendance. Of the group, ticket price $(M=3.79, S D$ $=1.94)$ and total cost of attendance $(M=3.71, S D=1.83)$ were the highest rated factors. Both of the parking factors scored very low. Ratings for ease of parking $(M=3.11, S D=$ 1.76) and parking costs $(M=2.73, S D=1.96)$ show that in general parking is the least influential of all external factors. It should be noted that the standard deviations for this section were as a whole higher than the other sections, showing some level of disagreement over the influence. However, the overall scores still show that cost and especially parking costs are of relatively low importance to determining attendance at women's basketball games.

The final part of the quantitative questioning asked respondents to consider what types of techniques for promoting attendance were most impactful for increasing attendance for women's basketball at their school. There were 23 different marketing techniques listed and participants were asked to rate each on the same seven point Likert scale. The standard deviations of all factors were consistent, with the lowest being 1.30 and the highest 1.77. These deviations showed far less fluctuation than the numbers calculated for the external factors. This indicates that the marketing employees generally have an idea of what techniques they think work most effectively for women's basketball. Communication between different schools to aid one another might also lead to a greater consensus on these techniques. Regardless, the ranking of techniques should provide 
clarity to any interested parties over what the field sees as most influential in increasing attendance.

Of all the marketing techniques listed, the highest rated was grassroots marketing $(M=5.08, S D=1.50)$. The exact methods used for grassroots marketing will be discussed later using the qualitative answers. Referrals and word of mouth was the next most important technique $(M=4.98, S D=1.58)$. Creating positive public relations was the third highest ranked $(M=4.83, S D=1.30)$, and the hosting of pre or post-game events was fourth $(M=4.79, S D=1.49)$. Group ticket sales was next $(M=4.72, S D=$ $1.64)$, followed by promotional giveaway items $(M=4.62, S D=1.59)$, use of Facebook $(M=4.60, S D=1.40)$ one game ticket discounts $(M=4.59, S D=1.77)$, and community service projects conducted by the women's basketball team $(M=4.56, S D=1.59)$. The least influential factor was the practice of telemarketing $(M=2.66, S D=1.38)$. Just above that were partial season ticket plans $(M=2.87, S D=1.69)$, public address announcements $(M=3.05, S D=1.44)$, and physical mail advertising $(M=3.08, S D=$ 1.51). It is clear that getting out into the public and creating a positive image of the program and players is vital for women's basketball. While having the results of techniques rated by the employees who use them regularly is very helpful, the qualitative responses to open-ended questions gave further detail to the reasons why particular strategies are more impactful and how to effectively use them.

\section{Discussion}

In addition to the quantitative results there were also opportunities for survey participants to explain their responses in greater detail. After review of the responses, several produced themes that detailed the factors influencing attendance.

Reasons for Meeting or Not Meeting Annual Attendance Goal

Following the question about whether or not the school had met its attendance goal for the 2011-12 women's basketball season there was an open-ended question asking, "Why do you think you did or did not meet your attendance goal?" With 58.82\% of the schools failing to meet their stated goals for the season there were more answers explaining that disappointment than those stating why they had succeeded.

In reviewing the answers, there were certain themes that appeared. The first of those was team performance on the court. This factor can cause attendance to go both ways; winning encourages attendance while losing causes fans to stay home. Fans can be very fickle, and even a successful season the previous year does not guarantee attendance will hold the following year. One respondent said, "This was a down season for our team coming off a twenty win season last year and playing in a post-season tournament. You can never count on wins or losses but it's easier to drive attendance when the teams are winning." It also seems that while a previous winning season brings no promises for the next year, a losing past year means the new season starts with a lack of energy and excitement. "The [beginning] of the season was a follow-up to two losing seasons in a row so interest was lacking from the start” noted another respondent. 
One method that does seem to be a way to renew interest in an unsuccessful program is to bring in a new coaching staff. With a new coach comes renewed optimism and interest in the program. One participant said, "We have hired a new women's head coach and we feel certain that she will turn our program around and bring back the excitement that once filled our gymnasium at women's basketball games”. This feeling was supported at several schools that just finished a year under a new coach as they noted an increase in excitement surrounding the program. While this buzz does not last forever, an optimistic, enthusiastic new coach can breathe life into a stale program and re-energize the fan base.

Several other internal factors that again are outside the control of most marketing employees include lack of budget for advertising, marketing staff turnover, and the surrounding market. A common response was "not enough time or money allocated to women's basketball." While this may always be an issue at many schools due to the other sports that take priority within an athletic department, it is something that can be offset through successful use of grassroots and free marketing. Multiple employees mentioned "marketing staff turnover in the middle of the season" as a reason why attendance goals were missed. This led to poor or no execution of planned promotions, which then further distanced fans from the program. Several respondents lamented that; "our geographical area presents a problem when it comes to other events in the area, beautiful weather, and traffic." Without question there are numerous factors outside the control of a typical college marketing director, but there are also numerous variables, which can be altered.

The main theme that arose for how attendance had been positively affected in the past year was the strategy to focus on several big games, rather than trying to push attendance at each and every home game. As one participant said, "I think the mistake we made was designating a promotion for every home game of the 2011-12 season rather than focusing in on 5 or 6 games and trying to pack the house for those designated games.” There are certain games against poor opponents or over holiday breaks that are unlikely to feature large crowds no matter how much effort is put into marketing. However, having some select games with heavily marketed promotions can lead to vibrant atmospheres several times a year. Common responses included "we had some unique game specific promotions which helped increase attendance" and "with themed events...we had great turnouts for select games." The nature of marketing women's basketball is that at most schools not every game will be well attended, but by focusing the limited resources available on a few bigger games rather than spreading, those out over the season the school can create some excitement in the women's basketball program. Other reasons mentioned for meeting the attendance goal included conference changes, reward programs, group promotions, and student attendance. Competition with larger sports on campus, high player turnover, and lack of doubleheaders were reported as negative influences.

Other External and Marketing Factors Affecting Attendance 
A response that frequently forwarded was the influence of weather on game attendance. Both good weather and bad weather can be reasons for why fans choose not to attend. In southern states where the weather is still warm during the winter this enjoyable climate can lead people to stay away from an indoor arena. However, far more responses brought up the issue of bad weather during the winter months in colder states. Even in states with "a very mild winter, people are very cautious about driving in the inclement weather" said one marketer. Another mentioned, "The weather plays a big factor in our attendance. If we have a game on a day with local school cancelling or constant snow it brings down our overall attendance numbers pretty quickly.” Another employee from a northern state put it simply; "if the weather is bad in any way, we always expect bad attendance.”

Another issue that was raised was the competition present in bigger cities. An employee from a large northeastern city mentioned, "there are 3 other schools in very close proximity with Division I basketball programs and also a thriving professional sports scene with which we are always competing for fans." In addition to other colleges and professional sports teams, high school sports were also expressed as competition for spectators. The general culture of the area was also an important outside factor mentioned. Some parts of the country are known as football or baseball areas and in these states no matter how successful or well marketed a women's basketball team is there may not be the level of interest needed to create a revenue producing program.

The last, but overwhelmingly most common response had to do with game scheduling. Although marketers do not have much control of this issue, they can influence certain aspects. The coaching staff and athletic department leadership typically do scheduling jointly, and while opponents are relatively unchangeable game days and start times can sometimes be adjusted. It is clear from the responses that weekend games; especially Friday and Saturday are by far the best draws. "Women's games have to be so carefully scheduled," said one respondent, "weeknight games are a killer. We have a hard time getting people to a men's game on a Tuesday night, let alone a women's game.” Many conferences also play games on Wednesday nights and these were mentioned repeatedly as bad for attendance, often due to community religious organizations that meet that night. Sunday games can be good draws, as long as they are after the NFL season has ended, although several Catholic schools stated that Sunday Mass could negatively affect attendance at women's basketball games. It was also frequently discussed that doubleheaders with men's basketball games are a boost to attendance. As mentioned by one marketer, "the doubleheaders really assisted us in our attendance numbers. We have to work a lot harder to get people to come out for the one women's game versus a doubleheader." While the number of games on a college basketball schedule means that by necessity some will have to be played on weeknights or other poor times, it is clear that college marketers should use any influence they can to push for important games to be scheduled on Fridays and Saturdays, in conjunction with the men's team if possible. While this may be impossible at larger schools, the smaller 
schools marketing departments noted they were able to have an influence on the scheduling of games.

Detail on Marketing Factors That Rated Very High or Very Low

Following the quantitative question asking participants to rate the list of marketing factors on a 7-point Likert scale there were two openings for them to comment further. One asked them to describe in more detail any factors they had rated very high and the other to talk about any they had rated very low. The highest rated marketing factor was grassroots marketing. Given the limited budgets mentioned earlier, this makes sense. There were many detailed responses describing the importance of grassroots work to drive attendance. "Grassroots and community service projects really boost attendance at women's basketball," said one respondent, "The fans of this sport want to feel connected with the team on a more individual level." Another stated,

We have noticed the more our team interacts with the community at large, the more groups we can target for ticket offers, and the better relationship our fans end up having with the team. This strong bond between fans and the team is crucial to bringing up attendance numbers because it becomes something the fans are invested in seeing.

As mentioned before budget is certainly a consideration on the importance of grassroots marketing. Grassroots "is really the only way to do it," said another response, "We don't have a huge marketing budget for women's basketball so you have to think of cheap, easy ways to get the word out there."

Referrals and word of mouth was the second highest rated factor and there were plenty of comments describing their importance. One respondent said,

So many people have said to me, 'my friend brought me to a women's game and

it was great, we loved it.' More and more we hear that it is word of mouth that is getting new people to a game. Once they come, they are hooked.

Another marketer added, "We rely most heavily on people coming and enjoying their experience and spreading the word. People who enjoy our venue and atmosphere are our best salesmen." A different response described word of mouth as "by far the most successful sales tool for us this past season."

Grassroots and referrals, as well as two other factors that scored well, creating positive public relations and community service projects, are all related to a large extent and based on the responses they are the most effective way to market women's basketball. Community service is a great way to boost the perception and awareness of the athletes. Said one participant, "community service events connect our student athletes with the community in ways which encourage reciprocal support of their endeavors." Not only does the work being done at these community projects benefit others, the goodwill created causes people to be more personally interested in the players. Added another, "the team being out in the community and creating a positive image is a huge benefit. If people like the team and the coach and the image they present, they will come to support the team." The core message from these four related and highly rated 
marketing factors is that, as a niche sport women's basketball cannot rely solely on athletic interest to draw fans; there must be a more personal connection with the people who attend games. "One of the biggest factors for our program is to create an image of our team that connects with the community," summarized another responder, "We want to have student-athletes that are personable and able to connect with our fan base." The most popular college sports, such as football and men's basketball may not have to reach out as much in order to create interest, but it is clear that for women's basketball creating a personal connection with the public is very important to boosting attendance.

Once you get people to the games, a way to increase connections and keep them coming back is through pre and post-game events. A few of the pre-game events mentioned include pizza for students, facility tours, youth sport clinics, fan item giveaways, and chalk talk with the coaches. Because players are getting ready for the game it is difficult to have them connect with fans prior, but post-game events offer another chance to get the players and spectators interacting. A particularly popular postgame activity is having a team autograph session after several games each year. On-court shoot-around with the team for children is another repeatedly mentioned activity. One unique event was to have a kid's press conference, where local children are able to pose as reporters to ask the team and coach questions about the game. The success of each activity often depends on the local climate and what people are interested in, but these events are just another way to create a positive public image around the community.

A third very important marketing technique that is becoming increasingly prevalent in women's basketball is the use of social media. Facebook and Twitter are the most well known social media networks and are thus the best ways to connect with fans. Perhaps the best aspect of social media is that it is free of charge. A survey participant stated, "Social media has been a great way to promote sports we do not have dollars to advertise for. Our Facebook and Twitter pages reach out to fans daily and promote women's basketball during the season.” Another responder stated bluntly, "If you aren't getting the word out on Facebook and Twitter you are probably wasting your time and money." While use of these networks really has no downside, it should be remembered that much of the target market for women's basketball is older and less willing to use these newer developments. As one subject said, "Our fan base in general is older and Twitter is not utilized very much at all. Facebook is a little better but still too young for our current database demographic.” Therefore while these two social networks may be a huge help in reaching many fans, there are other markets that do not use them and must be contacted using different methods. Other social networks mentioned occasionally include Living Social and Google+. Although not a traditional social network, Group On is also a new technology used to promote discounts, and the ease of sharing deals creates social interaction among fans in a different sense.

From the opposite perspective, there were some factors described as having little or no impact on attendance. Telemarketing was mentioned multiple times as a tactic that most schools do not use. If they do, it is only at rare times to promote a specific deal. 
Another tactic that was repeatedly brought up as ineffective is public address announcements. Despite their prevalence at sporting events, it seems that employees simply run them because it is the expected norm and not because they expect them to have any impact. As one marketer stated, "people often block out the public address announcements and simply pay attention to the activities on the court or personal things while the game is not going on.” Direct mail is still utilized but costs and lack of impact lead most schools only send out a few mailings each year. Outdoor advertising such as billboards and signage was also repeatedly mentioned as a little or unused tactic. In fact, some respondents stated that they literally have no marketing budget for women's basketball, so they can only use free forms of promotion.

An interesting theme that also arose from these responses was the perspective that for women's basketball, many schools choose not to promote individual players, but the team as a collective instead. "We don't promote individual players," summarized one marketer, "it is about the team and the overall environment." This does correlate somewhat to the most successful tactics of creating positive goodwill in the community. If just one or two players are out doing service it will not draw the attention that multiple players or the entire team can bring. By promoting the image of the whole team, marketers also distance the sport from the sometimes selfish or cocky attitudes of stars in many male sports. Finally, the theme of not trying to promote every game, but instead putting more effort into a few games was raised again on these questions, highlighting its' relevance to women's basketball.

Specific Promotions That Help Increase Attendance

The promotions that increased attendance during the academic year were events catered to youth. The most positively described events had a youth-centered focus. Some schools had specific games known as "Education Day" or something similar that was held during the day on a weekday. Children from local schools would be bused in and at several schools this was the highest attended game of the year. These games can benefit everyone, as described by one response, "The kids in the surrounding communities have the opportunity to come to a game during the day [for free] and the players are treated to a full house.” Even normal game times with a youth-focused event tended to increase attendance. Some of most commonly mentioned events included partnering with local organizations like Girl or Boy Scouts, hosting a "Take Your Kid to the Game" day, and getting youth basketball programs involved in halftime performances.

After youth events, the next most successful promotion involves raising funds for breast cancer research. Whether the school partners with the Play4Kay organization, or simply holds their own "Pink Night," survey respondents spoke positively about the attendance boost and overall atmosphere of the event. This is also a great way to get new spectators to attend a game. Describing one pink game a marketer mentioned, "we were able to get many groups out not because of the basketball game but because they wanted 
to support the cause." Even if many of the first time attendees do not come back, a few new fans might enjoy the core product and return.

Continuing with the focus of promoting several games heavily, a "Pack the House" game was mentioned as being very successful. For these games, a large proportion of the resources for the entire year are focused on promoting just this one game, and as a result, many produce season high attendance figures. In fact, one school went as far as creating a virtual season ticket package centered on one rival game. Fans, who purchased an $\$ 8$ ticket for that game, when ticket prices are normally $\$ 6$ and \$3, received free tickets to all remaining games. The responder from this school said,

The result of the promotion was we set the single game attendance record, and exceeded revenues from the previous year. The promotion also led to larger crowds than normal at all other games, because fans had tickets to those games. The larger crowds also led to more concessions and merchandise sales.

Not all "Pack the House" ticket sales feature a promotion this detailed, but focusing on driving sales for one or two big games is clearly a recurring theme from many different marketers. Other ways to drive ticket sales for games include heavy group discount packages. One type of promotion that had mixed results was an attempt to increase student attendance. Most schools responding to the survey cited a frustration with difficulties in improving the amount of students at each game. Free pizza and interaction with the coach worked on occasion, but the only method from any of the responses that resulted in sustained student attendance increases was some sort of rewards program for attending women's games. At schools where men's basketball game tickets are hard to obtain this can be very effective, because students who attend women's games get priority for purchase of men's tickets. However, this will only work if tickets for men's games are both in high demand and short supply.

\section{Conclusion}

Throughout the responses to all questions several main patterns emerged as the most important information that have the potential to increase attendance at women's basketball games. When it comes to external factors, factors outside the control of the marketing team, there was a pretty general consensus on what had the most influence on attendance. First was simply team success. The more games a team won, especially at home, the more interest it created in the program. Post season tournament runs and victories also helped carry momentum to the next year, while poor seasons mean the next year usually starts out without excitement. The main way to kick start a stalling program seems to be the hiring of a new coach who can energize the team and fan base. Weather is another significant factor affecting game attendance. Not only can good weather keep people from wanting to spend their time inside an arena, but also bad winter weather can prevent people from attending the games even if they want to be present. Another external factor is sport competition in the area. High school, college, and professional teams all provide other events for possible spectators to attend instead. Finally, within 
the athletic department things such as limited or no financial budget, low allocation of resources, and marketing staff turnover all prevent women's basketball from receiving the promotion needed to maintain attendance.

A factor that marketing employees have limited control over is scheduling. However, smaller programs reported that their marketing department does have an impact on scheduling. The responses made it clear that weekend games are highly preferred, and coordination with the men's schedule is vital. Of the variables that are completely within control of the athletic department it was obvious that the most important marketing tool is creating a positive public image through grassroots marketing, public appearances, and community service projects. Women's basketball programs must find something that differentiates it from the other more popular sports and create a connection with fans is a must. Once a fan exposed to women's basketball, they were likely to promote games to their friends and family, which is essentially free marketing for the school coming from a trustworthy source. Furthering these connections with pre and post-game events is also important for creating long-lasting support. Because of the limited marketing budget at most schools for women's basketball, free or cheap sources of advertising must be utilized. Social media networks like Facebook and Twitter are a great way to get regular reminders out to the fans.

A very prevalent theme was the importance of selecting certain games for which to increase marketing efforts, while letting some others be less attended. The nature of the schedule means that some games will not be sold out. But there are promotions that can lead to highly attended games at all schools. The limited resources available for marketing mean that these efforts need to be centered on a few of the biggest games against the most popular opponents. The atmosphere provided at these games not only benefits the players, but also increases the likelihood that fans will return for future home games. There are many different promotions that were mentioned in the responses, but there were a few that stood out as the most successful. Events that get local youth involved were the number one response. Pink games raising funds and awareness for cancer research were a close second. The importance of focusing on one or a couple "Pack the House" games was stated repeatedly. Finally, having special group ticket deals or $\$ 1$ ticket and concessions nights are additional ways to increase attendance at certain games.

The difficulty in marketing is that each market is different. Therefore, it is impossible to provide one blueprint that will work to boost attendance throughout the country. The most important thing is to know and connect with the local fan base. One highly effective way of learning the best methods to reach fans is to publish coupons or discounts using different sources and then tracking which ones bring in the most people. Only one school mentioned using this tactic, where they would, "include a coupon for the giveaway item on all print ads, email blasts, and Facebook posts. Fans would bring in the coupon for the give-away item and it would allow us to see where the fans were seeing our ads." The importance of methods similar to this that allow the marketing staff to 
better understand how to reach the community members cannot be overstated. It has been repeated how important it is to connect with people on a personal level, but without knowing what people want that is difficult to do. Once a program is able to create personal relationships with people in the community though, it can form a loyal fan base that will help spread the word about the product available at each home game. Recommendations for Future Research

This study is a beginning at understanding the marketing implications of intercollegiate women's basketball programs. The fan base for women's basketball is unique and in many instances untapped. This study sheds light on marketing strategies related specifically to women's basketball. However, further research is needed. More in-depth interviews with experienced marketers would be a way to increase the depth of knowledge in this area. The value of this study comes when combined with future research. Fans who attend women's basketball games and their perceptions are vital to understanding the marketing of women's basketball. We now know the perceptions of those involved in marketing of women's basketball. It is important that further research is conducted to determine methods to increase attendance at women's basketball games and largely untapped market. 


\section{References}

Cooper, C. G. (2011). The motivational preferences of consumers attending multiple NCAA wrestling events. Sport Marketing Quarterly, 20(1), 33-40.

Depken, C. A., Williams, C., \& Wilson, D. P. (2011). From the hardwood to the gridiron to the dorm: Influences on attendance to women's collegiate basketball. International Journal of Sport Finance, 6(1), 3-22.

DeSchriver, T. D. (1999). Factors affecting spectator attendance at NCAA Division II football contests. International Sports Journal, 3(2), 54-65

DeSchriver, T. D., \& Jensen, P. E. (2002). Determinants of spectator attendance at NCAA Division II football contests. Journal of Sport Management, 16(4), 311330.

Dick, R. J., \& Turner, B. A. (2007). Are fans and NBA marketing directors on the same page? A comparison of value of marketing techniques. Sport Marketing Quarterly, 16(3), 140-146.

Engleman, A. N., Pedersen, P. M., \& Wharton, R. (2009). Coverage by gender in ESPN the Magazine: An examination of articles and photographs. The International Journal of Sport Management. 10(2), 226-242.

Fink, J. S., Trail, G. T., \& Anderson, D. F. (2002). Environmental factors associated with spectator attendance and sport consumption behavior: gender and team differences. Sport Marketing Quarterly, 11(1), 8-19.

Fort, R. (2010). An economic look at the sustainability of FBS athletic departments. Journal of Intercollegiate Sport, 3(1), 3-21.

James, J. D., \& Ridinger, L. L. (2002). Female and male sport fans: A comparison of sport consumption motives. Journal of Sport Behavior, 25(3), 260-278.

Kahle, L, Duncan, M., Dalakas, V., \& Aiken, D. (2001). The social values of fans for men's versus women's university basketball. Sport Marketing Quarterly, 10(2), 156-162.

Liebert, P. (2008). A marketing plan for the 2009 NCAA women's basketball regional. Unpublished manuscript. Department of Parks, Recreation, and Tourism Management. North Carolina State University. Retrieved from http://repository.lib.ncsu.edu/dr/bitstream/1840.4/2010/1/Project_paper_pliebert.p df

Paule, A. L., \& Gilson, T. A. (2010). Current collegiate experiences of big-time, nonrevenue, NCAA athletes. Journal of Intercollegiate Sport, 3(2), 333-347.

Ridinger, L. L., \& Funk, D. C. (2006). Looking at gender differences through the lens of sport spectators. Sport Marketing Quarterly, 15(3), 155-166.

Shackelford, D., \& Greenwell, T. (2005). Predicting women's Division I sports attendance: An analysis of institutional characteristics. Sport Marketing Quarterly, 14(3), 139-147. 
Trail, G. T, \& Kyoum, K. (2011). Factors influencing spectator sport consumption: NCAA women's college basketball. International Journal of Sports Marketing \& Sponsorship, 13(1), 60-82.

Wells, D. E., Southall, R. M., \& Peng, H. H. (2000). An analysis of factors related to attendance at Division II football games. Sport Marketing Quarterly, 9(4), 203210.

Whiteside, E., Hardin, M., \& Ash, E. (2011). Good for society or good for business? Division I sports information directors' attitudes toward the commercialization of sports. International Journal of Sport Communication, 4(4), 473-491.

Whitney, J. D. (1988). Winning games versus winning championships: The economics of fan interest and team performance. Economic Inquiry, 26(4), 703-724.

Wolverton, B. (2012). Female participation in college sports reaches all-time high. The Chronicle of Higher Education. Retrieved from http://chronicle.com/article/Female-Participation-in/130431/ 


\section{About The Journal of SPORT}

The Journal of SPORT brings together in one journal the wide variety of research disciplines in sport and will be published biannually in Summer (July/August) and Winter (January/February). The Journal of SPORT is published by the Center for Sport and Recreation Development at Kent State University. A faculty Advisory Board composed of nationally, as well as internationally recognized faculty participates in the peer mentorship review process. This unique, but distinctive, mentorship process provides opportunities for graduate students, at an array of institutions, to thoroughly analyze and review research in conjunction with a faculty mentor. The number of articles accepted will be limited through a selective review process. After the faculty mentored peer review is completed a final determination is made to accept or reject the article. The Journal of $S P O R T$ encourages faculty and/or students to submit their research for review.

\section{Submission Guidelines}

See www.thejournalofsport.com for Submission Guidelines. 
About and Submission

Editor

Mark Lyberger

Kent State University

$\underline{\text { Production Coordinator }}$

Aaron Mulrooney

Kent State University 


\section{Student Review Board}

\section{T.J. Christie}

Kent State University

Jimmy Fetzer

Kent State University

Andrew Gerow

Kent State University

Sean Hanus

Kent State University

Karlie Hepburn

Kent State University

Ashley Just

Kent State University

Zach Keller

Kent State University 
Editorial Review Board (Volume 4 Issue 2)

Elizabeth Delia

Florida State University

\author{
Alan Kornspan \\ University of Akron \\ Jennifer Kulics \\ Kent State University \\ Sangkwon Lee \\ Texas A\&M University \\ Lawrence McCarthy \\ Seton Hall University \\ Kimberly Schimmel \\ Kent State University \\ Patrick Sweeney \\ Kent State University
}

